\title{
Complex Effects of Putative DRP-1 Inhibitors on Stress Responses in Mouse Heart and Rat Cardiomyoblasts ${ }^{[\mathrm{S}}$
}

\author{
Lauren Wendt, Jelena Vider, Louise E. See Hoe, Eugene Du Toit, Jason N. Peart, \\ and John P. Headrick
}

\author{
School of Medical Science, Griffith University, Southport, Australia (L.W., J.V., E.D.T., J.N.P., J.P.H.) and Critical Care Research \\ Group, The Prince Charles Hospital and The University of Queensland, Chermside, Australia (L.E.S.H.)
}

Received May 29, 2019; accepted September 12, 2019

\begin{abstract}
Dynamin-related protein-1 (DRP-1)-dependent mitochondrial fission may influence cardiac tolerance to ischemic or oxidative stress, presenting a potential "cardioprotective" target. Effects of dynamin inhibitors [mitochondrial division inhibitor 1 (MDIVI-1) and dynasore] on injury, mitochondrial function, and signaling proteins were assessed in distinct models: ischemia-reperfusion $(\mathrm{I}-\mathrm{R})$ in mouse hearts and oxidative stress in rat $\mathrm{H} 9 \mathrm{c} 2$ cardiomyoblasts. Hearts exhibited substantial cell death [approx. $40 \mathrm{IU}$ lactate dehydrogenase (LDH) efflux] and dysfunction (approx. 40 $\mathrm{mmHg}$ diastolic pressure, approx. $40 \%$ contractile recovery) following 25 minutes' ischemia. Pretreatment with $1 \mu \mathrm{M} \mathrm{MDIVI-1}$ reduced dysfunction (30 $\mathrm{mmHg}$ diastolic pressure, approx. $55 \%$ recovery) and delayed without reducing overall cell death, whereas $5 \mu \mathrm{M}$ MDIVI-1 reduced overall death at the same time paradoxically exaggerating dysfunction. Postischemic expression of mitochondrial DRP-1 and phospho-activation of ERK1/2 were reduced by MDIVI-1. Conversely, $1 \mu \mathrm{M}$ dynasore worsened cell death and reduced nonmitochondrial DRP-1. Postischemic respiratory fluxes were unaltered by MDIVI-1, although a $50 \%$ fall in complex-I flux control ratio was reversed. In H9c2 myoblasts stressed with $400 \mu \mathrm{M} \mathrm{H}_{2} \mathrm{O}_{2}$, treatment with $50 \mu \mathrm{M}$ MDIVI-1 preserved metabolic (MTT assay) and mitochondrial (basal respiration) function without influencing survival. This was associated with differential signaling responses, including reduced early versus increased late phospho-activation of ERK1/2,
\end{abstract}

increased phospho-activation of protein kinase B (AKT), and differential changes in determinants of autophagy [reduced microtubule-associated protein 1 light chain 3b (LC3B-II/I) vs. increased Parkinson juvenile disease protein 2 (Parkin)] and apoptosis [reduced poly-(ADP-ribose) polymerase (PARP) cleavage vs. increased BCL2-associated X (BAX)/B-cell lymphoma 2 (BCL2)]. These data show MDIVI-1 (not dynasore) confers some benefit during I-R/oxidative stress. However, despite mitochondrial and metabolic preservation, MDIVI-1 exerts mixed effects on cell death versus dysfunction, potentially reflecting differential changes in survival kinase, autophagy, and apoptosis pathways.

\section{SIGNIFICANCE STATEMENT}

Inhibition of mitochondrial fission is a novel approach to still elusive cardioprotection. Assessing effects of fission inhibitors on responses to ischemic or oxidative stress in hearts and cardiomyoblasts reveals mitochondrial division inhibitor 1 (MDIVl-1) and dynasore induce complex effects and limited cardioprotection. This includes differential impacts on death and dysfunction, survival kinases, and determinants of autophagy and apoptosis. Although highlighting the interconnectedness of fission and these key processes, results suggest MDIVI-1 and dynasore may be of limited value in the quest for effective cardioprotection.
L.W. was supported by a postgraduate scholarship from Griffith University, and L.E.S.H. was supported by a postgraduate scholarship from the National Heart Foundation of Australia. This research was supported by internal funds from Griffith University. The authors declare that there are no conflicts of interest.

Previous presentation of work at meetings: Wendt L, See Hoe L, Sachaphibulkij K, Du toit E, Peart J, Headrick J. (2015) Effects of dynaminrelated protein-1 (DRP-1) inhibition with MDIVI-1 on myocardial injury, mitochondrial respiration and stress-signalling in the murine heart. The FASEB Journal 29: 1 suppment, supplement 1026.2.

https://doi.org/10.1124/jpet.119.258897.

S This article has supplemental material available at jpet.aspetjournals.org.

\section{Introduction}

Mitochondrial phenotype governs cellular to systemic health and lies at the crossroads of cell survival and death. Unsurprisingly, adaptive quality control mechanisms have evolved, including dynamic fusion-mediated elongation versus fission-mediated fragmentation. This cycle contributes to maintenance of mitochondrial health in long-lived cardiomyocytes and neurons. Evidence of dysregulation with aging and disease has focused attention on fusion and fission as potential therapeutic targets (Ong and Hausenloy, 2010; Biala et al., 2015; Dorn, 2015). Fission is governed by dynamin-related

ABBREVIATIONS: AKT, protein kinase B; BAX, BCL2-associated X; BCL2, B-cell lymphoma 2; DMEM, Dulbecco's modified essential medium; DRP-1, dynamin-related protein-1; ECAR, extracellular acidification rate; FBS, fetal bovine serum; FCCP, 2-[[4-(trifluoromethoxy)phenyl] hydrazinylidene]propanedinitrile; I-R, ischemia-reperfusion; LC3B, microtubule-associated protein 1 light chain $3 \beta$; LDH, lactate dehydrogenase; MDIVI-1, mitochondrial division inhibitor 1; MTT, 3-(4,5-dimethylthiazol-2-yl)-2,5-diphenyltetrazolium bromide; OCR, oxygen consumption rate; OPA-1, optic atrophy-1; Parkin, Parkinson juvenile disease protein 2; PARP, poly-(ADP-ribose) polymerase; ROS, reactive oxygen species; TMRM, tetramethylrhodamine methyl ester perchlorate. 
protein (DRP-1) and fission 1 homolog protein (FIS1), and dynamin GTPase inhibitors such as mitochondrial division inhibitor 1 (MDIVI-1) and dynasore (dynamin inhibitor 1) have been tested for benefit (Reddy, 2014). Treatment with 5-50 $\mu \mathrm{M}$ MDIVI-1 reportedly conditions hearts against ischemia-reperfusion (I-R) injury (Ong et al., 2010, Sharp et al., 2014), and postischemic protection is evident with $25 \mu \mathrm{M}$ MDIVI-1 (Sharp et al., 2014). However, important questions remain regarding the cardioprotective utility, mechanisms, and selectivity of fission inhibitors (Preta et al., 2015; Rosdah et al., 2016; Smith and Gallo 2017).

Despite association of fission and cell death (Frank et al., 2001; Taguchi et al., 2007), underlying roles of dynamism proteins require delineation. This is highlighted by several observations: Increased fission fails to initiate death (Chen et al., 2005; Papanicolaou et al., 2012; Song et al., 2015; Song and Dorn, 2015) and improves stress-resistance (Papanicolaou et al., 2012); DRP-1-dependent fission can be antiapoptotic (Szabadkai et al., 2004); and DRP-1 inhibition/ downregulation may worsen myocardial infarction (Ikeda et al., 2015) and postischemic necroptosis (Dong et al., 2016) and apoptosis (Zhang et al., 2013). Such outcomes may reflect complex interactions between fission/fission proteins and autophagy (Dorn and Kitsis, 2015; Marín-Garcia and Akhmedov, 2016), survival kinase signaling (Gharanei et al., 2013; Gan et al., 2014; Lim et al., 2015), and cell death pathways (Dorn and Kitsis, 2015; Marín-Garcia and Akhmedov, 2016). Contributions of pleiotropic versus specific dynamism mechanisms are yet to be resolved. Indeed, cardiac benefits of fusion proteins may be largely pleiotropic in nature (Ong et al., 2017), and there is evidence MDIVI-1 and dynasore induce DRP-1-independent effects at concentrations employed to protect cells (Preta et al., 2015; Bordt et al., 2017; Smith and Gallo 2017). More fundamentally, active mitochondrial dynamism is not a feature of cardiomyocytes, which are dense with fragmented mitochondria (Song and Dorn, 2015) and may benefit from further fission (Papanicolaou et al., 2012).

We assessed effects of two distinct cell-permeable dynamin inhibitors (Fig. 1): MDIVI-1, a quinazolinone reportedly specific for DRP-1 inhibition at $\leq 25 \mu \mathrm{M}$ (Smith and Gallo, 2017), and dynasore, a semicarbazone that appears selective for dynamin/DRP-1 GTPase inhibition at $\leq 80 \mu \mathrm{M}$ (Macia et al., 2006). Given the conflicting effects of DRP-1 inhibition in different models (Ong and Hausenloy, 2010; Dong et al., 2016), and potential nonspecific actions (Preta et al., 2015; Smith and Gallo 2017; Bordt et al., 2017), we assessed impacts on markers of cell injury together with mitochondrial function and regulatory protein expression in two distinct models: I-R in mouse hearts and oxidative stress in rat cardiomyoblasts.

\section{Materials and Methods}

\section{Mice and Ethics}

Experiments were performed using young (9-12 week) male C57Bl/ 6J mice. Animals were purchased from the Animal Resources Center (Canning Vale WA, Australia) at 8 weeks of age and were habituated to the animal facility for a minimum of 7 days before use. Mice were housed in groups of four to five, with sawdust bedding and ad lib access to water and food throughout all studies. Animals were maintained in an artificial 12-hour day/night lighting cycle (lights on at 07:00) at a constant temperature of $21^{\circ} \mathrm{C}(40 \%$ humidity). A total of 50 mice were used, with none excluded from analysis. All investigations were

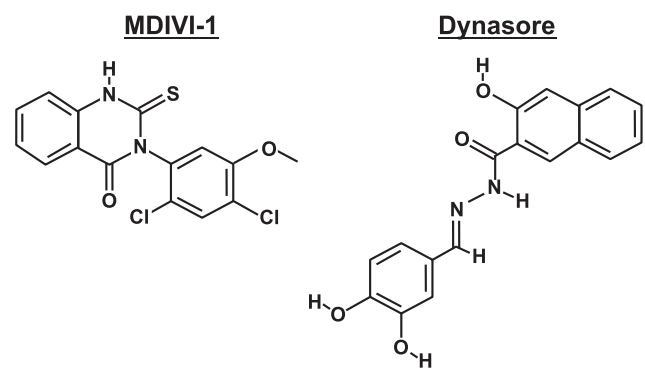

Fig. 1. Chemical structures of the putative DRP-1 inhibitors MDIVI-1 (PubChem CID: 3825829) and dynasore (PubChem CID: 136239889).

approved, under the guidelines of The Animal Care and Protection Act 2001, section 757, in accordance with Animal Ethics Committee of Griffith University, which is accredited by the Queensland Government, Department of Primary Industries and Fisheries (AEC number MSC/05/13 licensed to Jason N. Peart).

\section{Reagents}

The inhibitors MDIVI-1 (PubChem CID: 3825829) and dynasore hydrate (PubChem CID: 136239889) were purchased from SigmaAldrich (St. Louis, MO). Drug structures are shown in Fig. 1. Dulbecco's modified essential medium (DMEM), fetal bovine serum (FBS), and other tissue culture reagents were obtained from Life Technologies Inc. Tetramethylrhodamine methyl ester perchlorate (TMRM) was purchased from Molecular Probes (ThermoFischer Scientific, NJ). All other chemicals were purchased from Sigma-Aldrich.

\section{Perfused Heart Protocol and Experimental Groups}

Langendorff perfused hearts were prepared as detailed previously (Peart and Headrick, 2003; Reichelt et al., 2009). Briefly, mice were anesthetized with sodium pentobarbital $(60 \mathrm{mg} / \mathrm{kg}$ i.p.) and hearts excised and cannulated for Langendorff-perfusion with Krebs-Henseleit buffer $\left(119 \mathrm{mM} \mathrm{NaCl}, 11 \mathrm{mM}\right.$ glucose, $22 \mathrm{mM} \mathrm{NaHCO}_{3}, 4.7 \mathrm{mM} \mathrm{KCl}$, $1.2 \mathrm{mM} \mathrm{MgCl}_{2}, 1.2 \mathrm{mM} \mathrm{KH}_{2} \mathrm{PO}_{4}, 1.2 \mathrm{mM}$ EDTA, and $2.5 \mathrm{mM} \mathrm{CaCl}_{2}$ ) bubbled with $95 \% \mathrm{O}_{2} / 5 \% \mathrm{CO}_{2}$ to maintain $\mathrm{pH}$ at 7.4 at $37^{\circ} \mathrm{C}$ (Peart and Headrick, 2003; Reichelt et al., 2009). Perfusion fluid was delivered at a coronary pressure of $80 \mathrm{mmHg}$, with coronary flow rate monitored via an ultrasonic flow probe proximal to the aortic cannula and left ventricular isovolumic function assessed via a fluid-filled balloon inflated to an initial end-diastolic pressure of $5 \mathrm{mmHg}$ (Peart and Headrick, 2003; Reichelt et al., 2009). Hearts were then stabilized for a period of 20 minutes. No hearts met previously detailed exclusion criteria (Reichelt et al., 2009).

After 20 minutes' stabilization hearts were subjected to 25 minutes' global normothermic ischemia and 45 minutes' reperfusion. Coronary effluent was collected for analysis of lactate dehydrogenase (LDH) release, previously shown to correlate with infarction in this model (Peart and Headrick, 2003). Hearts were untreated (DMSO vehicle; $n=6)$ or received 1 or $5 \mu \mathrm{M}$ MDIVI- 1 or $1 \mu \mathrm{M}$ dynasore hydrate $(n=8$, 8 , and 6 , respectively), with infusion initiated 10-20 minutes prior to ischemia and maintained throughout reperfusion. These MDIVI-1 concentrations correspond to those that reportedly protected perfused hearts (Gao et al., 2013; Gharanei et al., 2013; Sharp et al., 2014) and were predicted to be selective for DRP-1 GTPase/fission inhibition (Cassidy-Stone et al., 2008; Numadate et al., 2014). The $1 \mu \mathrm{M}$ dynasore also mimicked a concentration that mediated protection in prior heart studies (Gao et al., 2013) and was predicted to be selective for inhibition of dynamin/DRP-1 GTPase activities (Macia et al., 2006).

\section{Mouse Heart Mitochondrial Respiratory Analyses}

Mitochondrial $\mathrm{O}_{2}$ consumption was quantified using an Oxygraph-2k instrument (Oroboros Instruments, Innsbruck, Austria) in shredded left 
ventricular myocardium from vehicle- and $1 \mu \mathrm{M}$ MDIVI-1treated hearts sampled: prior to ischemia ( $n=4$ and 6 , respectively), at 10 minutes' reperfusion ( $n=8$ for both groups), or 45 minutes' reperfusion ( $n=8$ for both groups). Oxygraph chambers were cleaned before each analysis and stabilized with Mir05 media before addition of shredded myocardium $(1 \mathrm{mg} / \mathrm{ml}$ in each chamber) and catalase $(280 \mathrm{IU} / \mathrm{ml})$. Mitochondrial respiration via complex I and complex II (at $37^{\circ} \mathrm{C}$ ) was interrogated via sequential addition of complex-specific substrates and inhibitors: complex I substrates ( $5 \mathrm{mM}$ pyruvate, $2 \mathrm{mM}$ malate, $10 \mathrm{mM}$ glutamate), complex II substrate (10 mM succinate), stimulation of oxidative phosphorylation ( $1 \mathrm{mM} \mathrm{ADP}$ ), and mitochondrial uncoupling $(0.5 \mu \mathrm{M}$ FCCP $)$.

\section{H9c2 Myoblast Studies}

To further explore the influences of MDIVI-1 on cardiac stress responses, we examined effects of MDIVI-1 on viability, mitochondrial membrane potential, and expression of DRP-1, optic atrophy-1 (OPA-1), and signaling proteins in $\mathrm{H} 9 \mathrm{c} 2$ cardiomyoblasts exposed to $\mathrm{H}_{2} \mathrm{O}_{2}$. The H9c2 cell line was obtained from the American Type Culture Collection (ATCC). Cells were maintained in high-glucose DMEM supplemented with $10 \% \mathrm{FBS}$, maintained under $95 \% \mathrm{O}_{2}$ and $5 \% \mathrm{CO}_{2}\left(37^{\circ} \mathrm{C}\right)$, and were passaged no more than 15 times. The H9c2 cells were grown to $70 \%-80 \%$ confluence in 100-mm plates before exposure to $400 \mu \mathrm{M}$ $\mathrm{H}_{2} \mathrm{O}_{2}$ for 60 minutes. Cells were untreated (DMSO vehicle) or treated with $50 \mu \mathrm{M}$ MDIVI-1 40 minutes prior to $\mathrm{H}_{2} \mathrm{O}_{2}$ exposure. A subset of cells was sampled after only 5 minutes' $\mathrm{H}_{2} \mathrm{O}_{2}$ for analysis of early ERK1/2 signaling. The $50 \mu \mathrm{M}$ MDIVI-1 replicates a concentration widely reported as mediating cytoprotection in myocardial cell models (Ong et al., 2010; (Yu et al., 2011a); Dong et al., 2016; Gao et al., 2016).

For analysis of cell death/cytotoxicity, release of LDH into the medium (IU/ml) was assayed enzymatically according to manufacturer's directions (Sigma-Aldrich). Assessment of metabolic activity was undertaken via the colorimetric MTT assay, according to manufacturer directions (Sigma-Aldrich), with reduction of the tetrazolium dye to colored formazan reflecting cellular NADPH-dependent oxidoreductase activity.

\section{H9c2 Mitochondrial Respiratory Analysis}

For respiratory analysis, H9c2 cells were plated $1.0 \times 10^{4}$ cells/well in eight-well XFp mini-plates in DMEM supplemented with $10 \% \mathrm{FBS}$ and Penstrep and left to attach overnight in an incubator $\left(37^{\circ} \mathrm{C} 5 \% \mathrm{CO}_{2} /\right.$ $95 \% \mathrm{O}_{2}$ ). Prior to analysis full media was replaced with XFp assay modified media ( $1 \mathrm{mM}$ pyruvate, $2 \mathrm{mM}$ glutamine, $10 \mathrm{mM}$ glucose, $\mathrm{pH}$ 7.4) and cells were incubated in a $37^{\circ} \mathrm{C}$ non- $\mathrm{CO}_{2}$ incubator for 45 minutes. Control and $\mathrm{H}_{2} \mathrm{O}_{2}(400 \mu \mathrm{M})$-challenged cells were pretreated with vehicle or $50 \mu \mathrm{M}$ MDIVI-1 or $50 \mu \mathrm{M}$ dynasore for 40 minutes. A Seahorse XFp Extracellular Flux Analyzer (Agilent Technologies Australia, Mulgrave VIC, Australia) was used to measure $\mathrm{O}_{2}$ consumption rate (OCR) and extracellular acidification rate (ECAR). Measurements were performed over 6 minutes in measurement cycles of four (basal metabolic rate) or three (to assess metabolic rate under mitochondrial stress conditions). After basal OCR was established, oligomycin $(1 \mu \mathrm{M})$, FCCP $(2 \mu \mathrm{M}$; concentration based on titration experiments), and rotenone + antimycin $\mathrm{A}(0.5 \mu \mathrm{M})$ were injected sequentially (see Fig. 11), and mitochondrial parameters determined: basal respiration $\left(\mathrm{OCR}_{\mathrm{Baseline}}-\mathrm{OCR}_{\text {Antimycin } \mathrm{A}+\text { Rotenone }}\right)$, nonmitochondrial respiration $\left(\mathrm{OCR}_{\text {Rotenone+Antimycin } \mathrm{A}}\right)$, ATP production $\left(\mathrm{OCR}_{\mathrm{Baseline}}\right.$

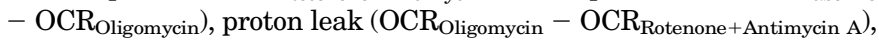
peak respiration $\left(\mathrm{OCR}_{\mathrm{FCCP}}-\mathrm{OCR}_{\mathrm{Rotenone}+\text { Antimycin } \mathrm{A}}\right)$, spare capacity $\left(\mathrm{OCR}_{\mathrm{FCCP}}-\mathrm{OCR}_{\mathrm{Baseline}}\right)$. All measurements were normalized to protein content per well. Data were analyzed by Seahorse Wave Software (Agilent) using report generator.

\section{Protein Analysis}

Tissue Extraction. Postischemic protein expression was assessed in ventricular myocardium sampled at 45 minutes' reperfusion $(n=6$,
8, and 6 for control, $1 \mu \mathrm{M}$ MDIVI-1, and $1 \mu \mathrm{M}$ dynasore groups, respectively). Tissue was sectioned and homogenized in a glass dounce with $1.0 \mathrm{ml}$ of ice-cold isolation buffer containing protease and phosphatase inhibitors (70 mM sucrose, $190 \mathrm{mM}$ mannitol, $20 \mathrm{mM}$ HEPES, and $0.2 \mathrm{mM}$ EDTA, $1 \mathrm{mM}$ phenylmethylsulfonyl fluoride, $10 \mu \mathrm{M}$ leupeptin, $3 \mathrm{mM}$ benzamidine, $5 \mu \mathrm{M}$ pepstatin $\mathrm{A}, 1 \mathrm{mM} \mathrm{NaO}$ ). Whole homogenate samples were removed and stored in lysis buffer for later analysis. Tissue homogenates underwent centrifugation at $600 \mathrm{~g}$ ( $\mathrm{rcf}$ ) for 10 minutes at $4^{\circ} \mathrm{C}$. The supernatant was removed and the nuclear pellet washed, spun at $600 \mathrm{~g}$ for 10 minutes, before resuspension in lysis buffer and storage. The supernatant containing mitochondria, cytosol, and plasma membrane was centrifuged at $10,000 \mathrm{~g}$ for 30 minutes, and the mitochondria-enriched pellet resuspended in lysis buffer.

For H9c2 myoblasts, cells were harvested, washed with PBS, and suspended in $150 \mu \mathrm{l}$ of ice-cold lysis buffer [0.1\% Triton-X; $20 \mathrm{mM}$ 4-morpholinepropanesulfonic acid (MOPS), $2 \mathrm{mM}$ EGTA, $5 \mathrm{mM}$ EDTA, $30 \mathrm{mM}$ sodium fluoride, $20 \mathrm{mM}$ sodium tetra-pyrophosphate, $10 \mu \mathrm{M}$ leupeptin, $5 \mu \mathrm{M}$ pepstatin $\mathrm{A}, 3 \mathrm{mM}$ benzamidine, $1 \mathrm{mM}$ phenylmethanesulfonyl fluoride, $1 \mathrm{mM}$ sodium orthovanadate]. Cell lysates were frozen at $-80^{\circ} \mathrm{C}$ until analysis. Thawed samples were prepared in required volumes with loading dye and denatured at $95^{\circ} \mathrm{C}$ for 5 minutes in a heating block.

Protein concentrations were determined using a BCA assay in a 96-well microplate (Pierce BCA protein assay kit), with absorbance measured at $562 \mathrm{~nm}$ (infinite M200 Pro; Tecan, Mannedorf, Switzerland). Aliquots of $20 \mu \mathrm{g}$ of protein were prepared with appropriate volumes of Kinexus buffer and protease inhibitors (20 mM MOPS, 2 mM EGTA; 5 mM EDTA; 30 mM sodium fluoride; $40 \mathrm{mM} \beta$-glycerophosphate; and $20 \mathrm{mM}$ sodium tetra-pyrophosphate) and stored at $-80^{\circ} \mathrm{C}$ until analysis.

Electrophoresis. Myocardial or cell fractions containing equal quantities of protein were loaded onto hand-cast $10 \%$ acrylamide gels and separated in a Bio-Rad electrophoresis chamber at $150 \mathrm{~V}$ for 80 minutes. Transfer of proteins was achieved using a polyvinylidene difluoride fluorescence membrane at a $350 \mathrm{~mA}$ current for approx. 2 hours and blocked with Odyssey blocking buffer for a further 2 hours at room temperature. Transferred proteins were incubated with primary antibody (dilution $1: 750$ to $1: 1000$ ) for $15-18$ hours at $4^{\circ} \mathrm{C}$ with gentle rocking. The polyvinylidene difluoride fluorescence membrane was washed in Tris-buffered saline for 5 minutes and again in Tris-buffered saline/Tween 20 (four cycles of 5 minutes) before incubation with secondary antibody at room temperature in the dark. Membranes were subsequently visualized on a Li-Cor Odyssey Infrared Imaging System (Li-Cor Biosciences, Lincoln, NE) with protein densitometry normalized to an internal standard and loading control.

\section{Statistical Analyses}

Data are expressed as means \pm S.E.M. Differences between two or more groups were tested via one- or two-way ANOVA, with a Newman-Keuls post-hoc test applied when significant effects were detected. Significant differences were accepted for $P<0.05$. All tests were performed with Prism 6 (GraphPad Software Inc., La Jolla, CA).

\section{Results}

\section{Mouse Heart Model}

Effects of DRP-1 Inhibitors on Baseline Function and Ischemic Contracture. Baseline contractile function and coronary flow were not significantly modified by either 1 or $5 \mu \mathrm{M}$ MDIVI-1, or $1 \mu \mathrm{M}$ dynasore (Table 1 ). As a gauge of potential benefit during ischemia itself we assessed rate and extent of ischemic contracture development. Onset of ischemic contracture, defined here as an increase of $\geq 20 \mathrm{mmHg}$ above 
preischemic pressure, occurred after approx. 270 seconds in untreated hearts, with a peak pressure of $80 \mathrm{mmHg}$ achieved at approx. 400 seconds (Fig. 2 ). Treatment with $1 \mu \mathrm{M}$ MDIVI-1 or dynasore failed to influence contracture, whereas $5 \mu \mathrm{M}$ MDIVI-1 was significantly protective (reducing both rate of and peak contracture).

Effects of DRP-1 Inhibitors on I-R Injury. Left ventricular developed pressure (LVDP) gradually recovered to approx. $40 \%$ of preischemic levels during 45 minutes' reperfusion in untreated hearts (Fig. 3). Treatment with $1 \mu \mathrm{M}$ MDIVI-1 significantly improved final recoveries of left ventricular diastolic, systolic, and developed pressures (Fig. 3). Paradoxically, $5 \mu \mathrm{M}$ MDIVI-1 appeared to modestly worsen recovery of contractile function, and $1 \mu \mathrm{M}$ dynasore was without effect (Fig. 3).

Efflux of LDH was employed as a biomarker of cell death. We assessed total postischemic death and, in the case of $1 \mu \mathrm{M}$ MDIVI-1, early damage over the initial 10 minutes of reperfusion. Total postischemic LDH efflux was unaltered with $1 \mu \mathrm{M}$ MDIVI-1 (Fig. 4A); however, early LDH efflux during the first 10 minutes reperfusion was substantially reduced by $>60 \%$ (Fig. 4B). A higher $5 \mu \mathrm{M}$ MDIVI-1 concentration significantly reduced overall cell death. Conversely, LDH efflux was increased in hearts treated with $1 \mu \mathrm{M}$ dynasore (Fig. 4A).

Effects of DRP-1 Inhibitors on DRP-1 and Survival Kinases. Data indicate MDIVI-1 reduces mitochondrial DRP1 expression without substantially influencing nonmitochondrial levels in postischemic myocardium (Fig. 5). In contrast, dynasore significantly reduced nonmitochondrial DRP-1 without influencing mitochondrial levels. The phosphorylation state of ERK1/2 at 10 minutes of reperfusion was significantly reduced in the nonmitochondrial fraction (Fig. 6, B and C). Postischemic AKT expression and phosphorylation were unaltered by MDIVI-1 (Fig. 6, D-F).

Effects of DRP-1 Inhibitors on Postischemic Respiratory Function. Substrate-dependent mitochondrial respiration was assessed in shredded myocardium from hearts subjected to normoxic perfusion, or 10 or 45 minutes' postischemic reperfusion ( $\pm 1 \mu$ M MDIVI-1) (Fig. 7). Progressive reductions (up to $50 \%$ ) in complex I activity, and the complex I flux control ratio, were evident during reperfusion (Fig. 7). Other respiratory parameters were relatively insensitive to I-R (Fig. 7). Treatment with MDIVI-1 did not significantly alter $\mathrm{O}_{2}$ fluxes under normoxic or postischemic conditions. However, the postischemic decline in complex I flux control ratio was countered by MDIVI-1 (Fig. 7).
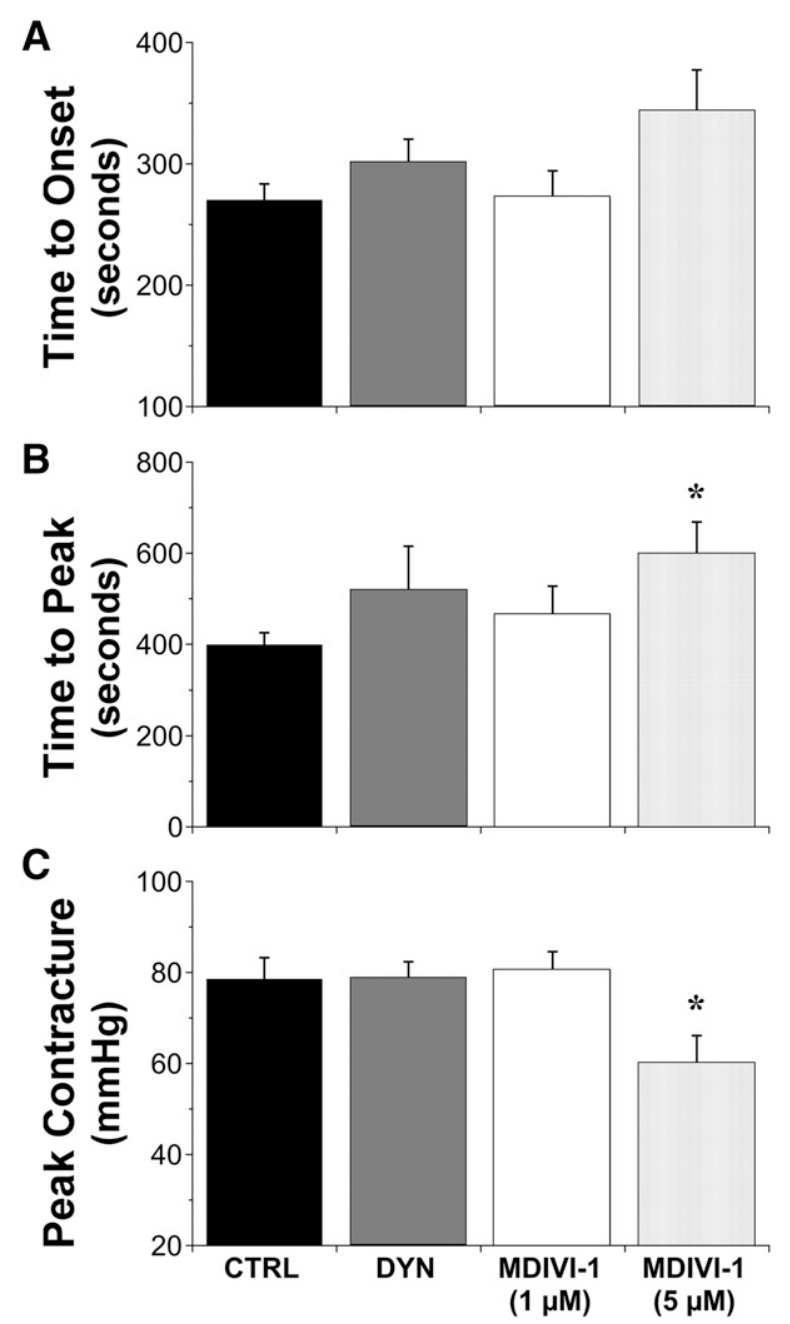

Fig. 2. Impacts of MDIVI-1 and dynasore on myocardial ischemic contracture. Hearts were untreated (CTRL) or pretreated with $1 \mu \mathrm{M}$ dynasore (DYN) or 1-5 $\mu$ M MDIVI-1 10 minutes prior to and throughout I-R. (A) Time to ischemic contracture, (B) time to peak ischemic contracture, (C) peak ischemic contracture. Data are means \pm S.E.M. ( $n=6-8$ /group). ${ }^{*} P<0.05$ vs. CTRL; by one-way ANOVA and NewmanKeuls post-hoc test.

\section{Rat H9c2 Model}

Effects of MDIVI-1 on Cytotoxicity, Metabolic Activity, Mitochondrial Membrane Potential, and Morphology. Exposure of $\mathrm{H} 9 \mathrm{c} 2$ cells to $\mathrm{H}_{2} \mathrm{O}_{2}$ for 60 minutes resulted in a $25 \%$ fall in metabolic activity (MTT assay) and significant cytotoxicity (100\% increase in LDH release) (Fig. 8).

TABLE 1

Function in ex vivo hearts prior to and after infusion of DRP-1 inhibitors

Functional measures were made prior to and after 10 minutes of drug (or vehicle) infusion. Data are means \pm S.E.M. No significant differences were detected pre- vs. post-treatment.

\begin{tabular}{lccccc}
\hline Treatment & Pre-/Postinfusion & End Diastolic Pressure & Systolic Pressure & Developed Pressure & Coronary Flow \\
\hline \multirow{4}{*}{ Vehicle $(n=6)$} & & $m m H g$ & $m m H g$ & $m m g$ & $\mathrm{ml} / \mathrm{min}$ \\
& & $5 \pm 1$ & $134 \pm 3$ & $128 \pm 6$ & $3.1 \pm 0.2$ \\
$1 \mu \mathrm{M}$ Dynasore $(n=6)$ & Post- & $5 \pm 1$ & $132 \pm 4$ & $126 \pm 6$ & $3.4 \pm 0.3$ \\
& Pre- & $4 \pm 1$ & $135 \pm 6$ & $131 \pm 6$ & $2.9 \pm 0.2$ \\
$1 \mu \mathrm{M}$ MDIVI-1 $(n=8)$ & Post- & $4 \pm 1$ & $133 \pm 7$ & $129 \pm 7$ & $3.4 \pm 0.2$ \\
& Pre- & $5 \pm 1$ & $122 \pm 6$ & $117 \pm 6$ & $2.6 \pm 0.2$ \\
$5 \mu \mathrm{M}$ MDIVI-1 $(n=8)$ & Post- & $6 \pm 1$ & $120 \pm 6$ & $114 \pm 7$ & $3.2 \pm 0.2$ \\
& Pre- & $7 \pm 1$ & $144 \pm 8$ & $124 \pm 9$ & $2.7 \pm 0.2$ \\
& Post- & $6 \pm 1$ & $137 \pm 8$ & $120 \pm 10$ & $2.9 \pm 0.2$ \\
\hline
\end{tabular}




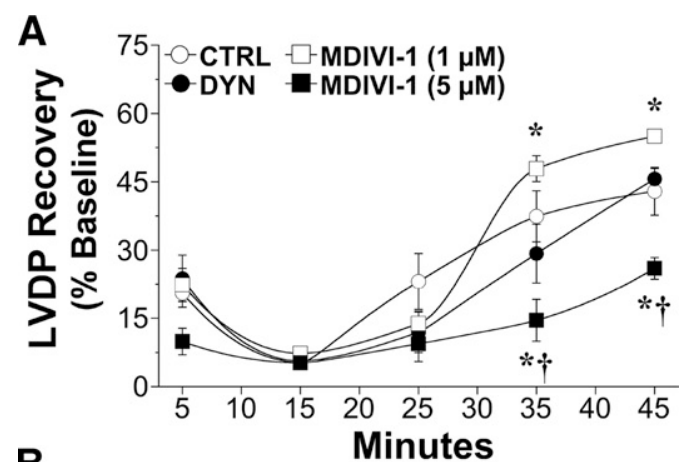

B
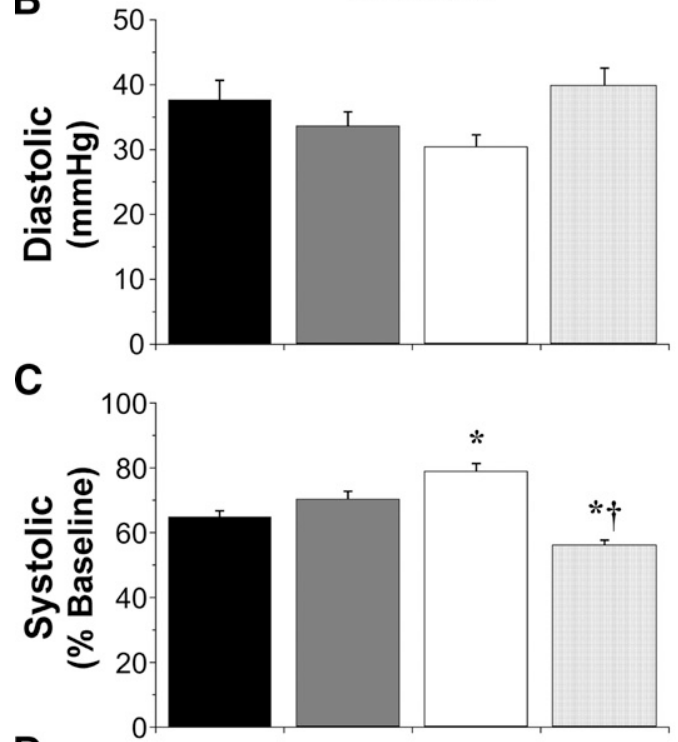

D

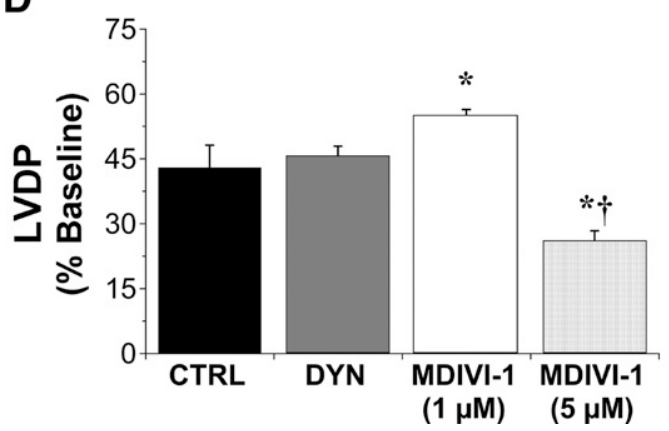

Fig. 3. Effects of MDIVI-1 and dynasore on myocardial dysfunction postischemia. Postischemic functional recoveries are shown for untreated (CTRL) hearts and hearts treated with $1 \mu \mathrm{M}$ dynasore (DYN) or $1-5 \mu \mathrm{M}$ MDIVI-1 10 minutes prior to and throughout I-R. (A) Patterns of recovery for left ventricular developed pressure (LVDP) and final recoveries for (B) end-diastolic, (C) systolic, and (D) developed pressures. Data are means \pm S.E.M. ( $n=6-8$ /group). $* P<0.05$ vs. untreated (CTRL) $\dagger P<0.055$ vs. $1 \mu \mathrm{M}$ MDIVI-1; by two-way ANOVA (A) and one-way ANOVA (B and C) and Newman-Keuls post-hoc test.

Interestingly, treatment with $50 \mu \mathrm{M}$ MDIVI-1 alone appeared to induce some cytotoxicity under baseline conditions and failed to reduce cytotoxicity during $\mathrm{H}_{2} \mathrm{O}_{2}$ challenge. However, MDIVI-1 significantly inhibited $\mathrm{H}_{2} \mathrm{O}_{2}$-dependent changes in metabolic activity. Fluorescent imaging of H9c2 cells (Supplemental Fig. 1) confirmed substantial mitochondrial fragmentation with $\mathrm{H}_{2} \mathrm{O}_{2}$ that was inhibited by MDIVI-1 and dynasore. Curiously, imaging suggested some fragmentation in response to the inhibitors alone. Preliminary flow cytometric analysis of the mitochondrial membrane potential $\left(\Delta \psi_{\mathrm{m}}\right)$ using a potentially high quenching $100 \mu \mathrm{M}$ TMRM concentration suggested a $20 \%$ fall in membrane potential with $\mathrm{H}_{2} \mathrm{O}_{2}$, an effect reversed by MDIVI-1 (Supplemental Fig. 2), whereas flow cytometric analysis with nonquenching $20 \mathrm{nM}$ TMRM suggested mitochondrial membrane potential might have been slightly reduced with MDIVI-1 or dynasore treatment, as shown by increased MitoTracker green mean fluorescence intensity with MDIVI-1 treatment. (Supplemental Fig. 3).

Effects of MDIVI-1 on Fission, Fusion, Autophagy, Apoptosis, and Survival Kinase Signaling. Expression of DRP-1 was reduced by $\mathrm{H}_{2} \mathrm{O}_{2}$, an effect attenuated by MDIVI-1 (Fig. 9A). Conversely, the fusion protein OPA1 was increased with $\mathrm{H}_{2} \mathrm{O}_{2}$, an effect also countered by MDIVI-1 (Fig. 9B). Expression levels for reduced microtubule-associated protein 1 light chain 3b (LC3B-II/I) and Parkinson juvenile disease protein 2 (Parkin) were increased with $\mathrm{H}_{2} \mathrm{O}_{2}$ stress, whereas the LCB3-II/1 ratio was not significantly altered (Fig. 9, C-E). Treatment with MDIVI-1 countered the rise in LC3B-II and reduced the LCB3-II/1 ratio and augmented Parkin expression. Exposure to $\mathrm{H}_{2} \mathrm{O}_{2}$ induced proapoptotic changes, significantly increasing the BCL2-associated X (BAX)/B-cell lymphoma 2 (BCL2) ratio and poly-(ADP-ribose) polymerase (PARP) cleavage (Fig. 9, F-H). MDIVI-1 exaggerated the BAX/BCL2 response and countered PARP cleavage.

Exposure to $\mathrm{H}_{2} \mathrm{O}_{2}$ triggered phospho-activation of ERK1/2 and AKT, with total ERK1/2 unchanged and total AKT falling by approx. 50\% (Fig. 10). Final phospho-activation of ERK1/2 and AKT was augmented by MDIVI-1, whereas early activation of ERK1/2 was reduced (Fig. 10B). Treatment with MDIVI-1 resulted in a small (approx. 10\%) decrease in ERK1/2 expression during $\mathrm{H}_{2} \mathrm{O}_{2}$ challenge and inhibited early ERK1/2 phospho-

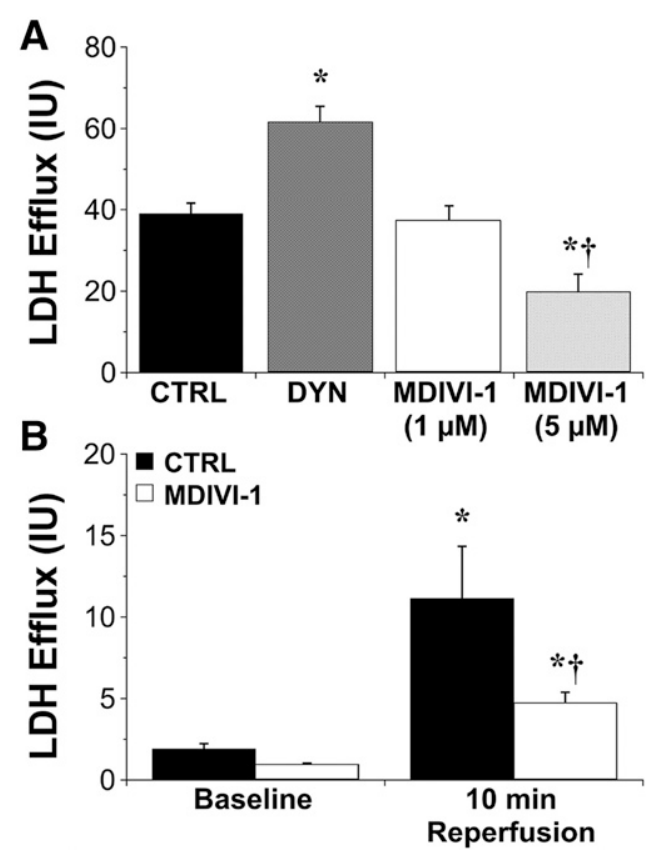

Fig. 4. Effects of DRP-1 inhibitors on postischemic LDH efflux. (A) Total lactate dehydrogenase (LDH) efflux throughout 25 minutes' ischemia/45 minutes' reperfusion in untreated hearts (CTRL) and hearts treated with $1 \mu \mathrm{M}$ dynasore (DYN) or 1-5 $\mu \mathrm{M}$ MDIVI-1 10 minutes prior to and throughout I-R. (B) Early LDH release over initial 10 minutes' reperfusion in hearts untreated or treated with $1 \mu \mathrm{M}$ MDIVI-1. Efflux is shown in international units (IU). Means \pm S.E.M. ( $n=6$-8/group). ${ }^{*} P<0.05$ vs. untreated (CTRL) or Baseline; $† P<0.055$ vs. $1 \mu \mathrm{M}$ MDIVI-1; by one-way ANOVA and Newman-Keuls post-hoc test. 

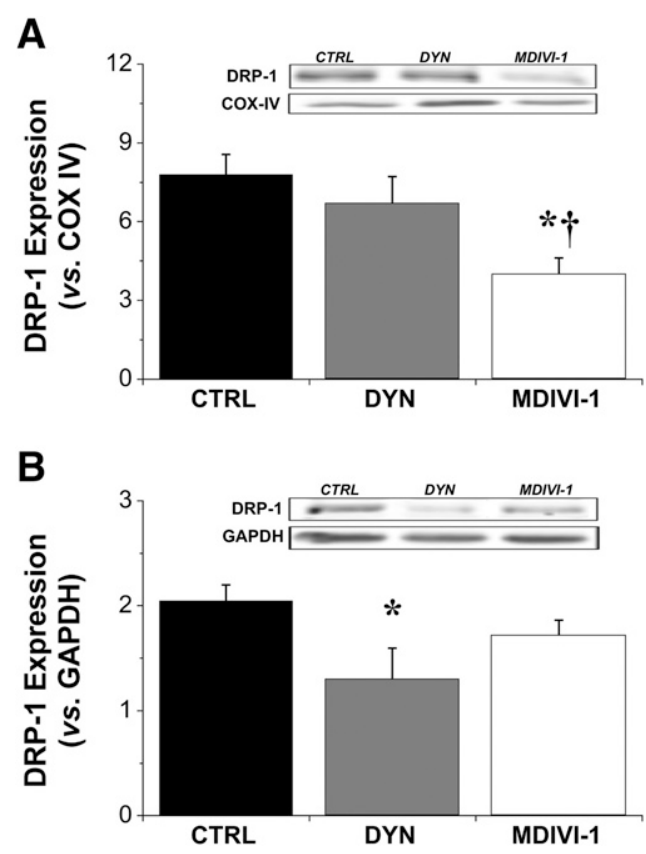

Fig. 5. Effects of DRP-1 inhibitors on postischemic DRP-1 expression. Relative expression of DRP-1 in (A) mitochondrial and (B) nonmitochondrial fractions from hearts subjected to 25 minutes' ischemia and 45 minutes' reperfusion. Perfused hearts were untreated (CTRL), or treated with $1 \mu \mathrm{M}$ dynasore (DYN) or MDIVI-1 10 minutes prior to and throughout I-R. Data are means \pm S.E.M. $(n=6-8$ /group $) . * P<0.05$ vs. untreated (CTRL); $\uparrow P<0.05$ vs. dynasore (DYN); by one-way ANOVA and Newman-Keuls post-hoc test.

activation ( 5 minutes' $\mathrm{H}_{2} \mathrm{O}_{2}$ ) but exaggerated late activation (Fig. 10B). Baseline AKT expression was moderately suppressed by MDIVI-1, with expression during $\mathrm{H}_{2} \mathrm{O}_{2}$ unaltered by the inhibitor (Fig. 10C). Pronounced phospho-activation of AKT with $\mathrm{H}_{2} \mathrm{O}_{2}$ was exaggerated by MDIVI-1 (Fig. 10D).

Effects of MDIVI-1 and Dynasore on Mitochondrial Respiratory and Glycolytic Function. Mitochondrial stress analysis using the Seahorse XFp Extracellular Flux Analyzer demonstrated that $\mathrm{H}_{2} \mathrm{O}_{2}$ significantly reduced $\mathrm{O}_{2}$ consumption (basal, maximal, and spare consumption, and nonmitochondrial) and ATP production without influencing the proton leak (Fig. 11). Neither agent (at relatively high and potentially less specific concentrations of $50 \mu \mathrm{M}$ ) modified respiratory rates or proton leak in nonstressed cells, and both induced similar effects in $\mathrm{H}_{2} \mathrm{O}_{2}$ stressed cells: partially countering the effects of $\mathrm{H}_{2} \mathrm{O}_{2}$ on nonmitochondrial $\mathrm{O}_{2}$ consumption, selectively increasing proton leak in $\mathrm{H}_{2} \mathrm{O}_{2}$ challenged cells, and eliminating the effects of $\mathrm{H}_{2} \mathrm{O}_{2}$ on basal respiration (Fig. 11).

The basal ECAR, a measure of glycolytic lactate production, was highest in MDIV-1 and lowest in $\mathrm{H}_{2} \mathrm{O}_{2}$-treated cells (Fig. 11). Oxidative stress limited glycolytic activity during mitochondrial uncoupling, paralleling effects on $\mathrm{O}_{2}$ consumption. Both inhibitors partially countered the effects of $\mathrm{H}_{2} \mathrm{O}_{2}$ on basal ECAR and peak glycolytic capacity during uncoupling. The OCR/ECAR ratio, reflecting preference for oxidative phosphorylation versus glycolysis in coupled mitochondria, was relatively insensitive to both $\mathrm{H}_{2} \mathrm{O}_{2}$ stress and the DRP-1 inhibitors.

\section{Discussion}

The roles of DRP-1 in myocardial-stress resistance, and mechanisms by which inhibitors modify injury, remain unclear.
Although reportedly protective in hearts (Ong et al., 2010; Gao et al., 2013; Gharanei et al., 2013; Sharp et al., 2014), DRP-1 inhibition can also increase postischemic death in cardiac (Dong et al., 2016) and neuronal cells (Zhang et al., 2013). Data here support some benefit with MDIVI-1, but not dynasore, during myocardial ischemia and early reperfusion, including preserved respiratory control and delayed or reduced necrotic death (Table 2). Studies in cardiomyoblasts also support partial metabolic and mitochondrial protection, although cell death was unaltered. Complex effects on survival kinase, autophagy, and apoptosis signaling (summarized in Table 2) may underpin these mixed outcomes, and DRP-1 independent mechanisms cannot be excluded.

DRP-1 Inhibition in Cardioprotection. Although mitochondrial dynamism is not a feature of healthy myocardium (Song and Dorn, 2015) and, despite evidence increased fission can be protective (Papanicolaou et al., 2012), it is possible stressors may promote an excessive and injurious fission. Preand postischemic MDIVI-1 reportedly reduces cardiac injury, mitochondrial dysfunction, and fission when applied at 5 (Sharp et al., 2014) or $50 \mu \mathrm{M}$ (Ong et al., 2010). We found $1 \mu \mathrm{M}$ MDIVI-1 limited postischemic dysfunction and delayed cell death, whereas $5 \mu \mathrm{M}$ MDIVI-1 reduced necrotic death and ischemic contracture yet paradoxically worsened dysfunction (Table 2). A dissociation of functional and survival outcomes with DRP-1 inhibitors agrees with prior reports (Gharanei et al., 2013; Sharp et al., 2014). In cardiomyoblasts MDIVI-1 also improved metabolic and mitochondrial responses without altering survival. Curiously, oxidative stress in myoblasts induced changes predicted to favor fusion (reduced DRP-1 vs. increased OPA-1), with MDIVI-1 countering these changes.

Benefit with MDIVI-1 during ischemia and early reperfusion is consistent with preconditioning effects of the compound (Ong et al., 2010; Sharp et al., 2014; Dong et al., 2016) and may reflect inhibition of the early fission shown to be rapidly induced during ischemia in other cell types (Kumar et al., 2016). Subsequent perturbations of kinase, autophagy, and death signaling during later reperfusion (Table 2) may induce additional effects, potentially exaggerating injury (Zhang et al., 2013; Dong et al., 2016). Contrasting MDIVI-1, dynasore worsened death in reperfused hearts without influencing dysfunction. Although speculative, this may reflect other influences of dynasore, which interferes with dynamindependent endocytosis (Macia et al., 2006) and disrupts membrane cholesterol and lipid rafts (Preta et al., 2015).

These distinct and paradoxical effects of MDIVI-1 and dynasore in different models raise questions regarding selectivities and mechanisms. Although mechanisms were not directly addressing here, both inhibitors promote mitochondrial elongation in stressed myoblasts (Supplemental Fig. 1), and MDIVI-1 reduced mitochondrial DRP-1 in postischemic myocardium, consistent with prior observations (Ong et al., 2010; Sharp et al., 2014; Dong et al., 2016). In contrast, dynasore modified nonmitochondrial DRP-1 in stressed hearts, suggesting differing specificities. Dynasore inhibits dynamin 1/2 GTPase activities with an $\mathrm{IC}_{50}$ of $12-15 \mu \mathrm{M}$ and exerts similar inhibitory effects on DRP-1 GTPase activity without influencing other related or unrelated GTPases (Macia et al., 2006). The $1 \mu \mathrm{M}$ concentration applied in hearts is thus considered to be relatively selective for dynamin/DRP1 inhibition. Higher concentrations are employed to inhibit endocytosis, which may participate in either cardiac injury 

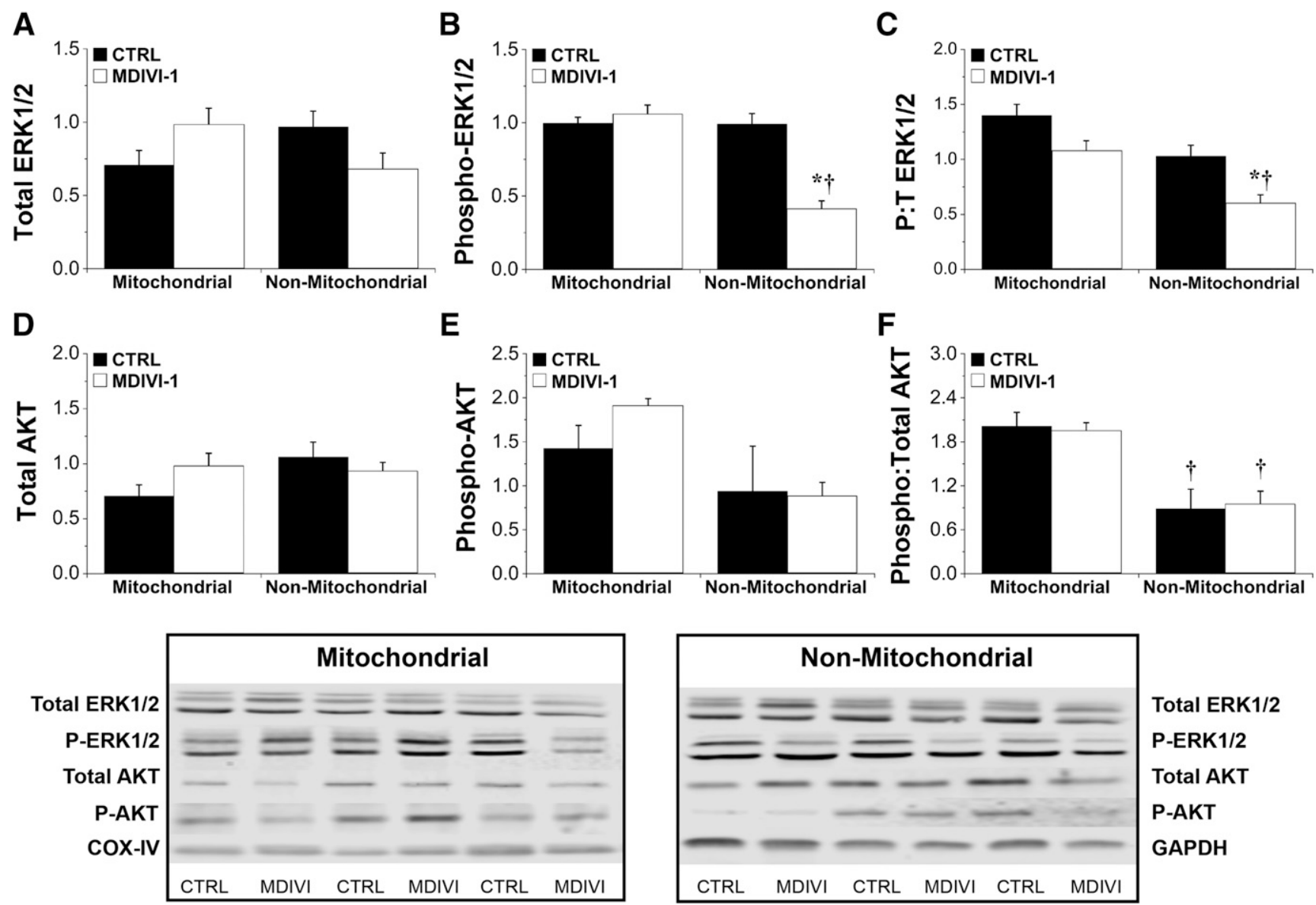

Fig. 6. Effects of MDIVI-1 on postischemic ERK1/2 and AKT expression and phosphorylation. Mitochondrial and nonmitochondrial fractions from hearts reperfused for 10 minutes following 25 minutes' ischemia were assessed for: (A) total ERK1/2, (B) phosphorylated ERK1/2, (C) the ratio of phosphorylated to total ERK1/2, (D) total AKT, (E) phosphorylated AKT, and (F) the ratio of phosphorylated to total AKT. Hearts were untreated (CTRL) or treated with $1 \mu \mathrm{M}$ MDIVI-1 10 minutes prior to and throughout I-R. Lower panel presents immunoblot images for total and phosphoproteins in mitochondrial and nonmitochondrial fractions. Mitochondrial expression normalized to COX-IV, nonmitochondrial expression to GAPDH. Data are means \pm S.E.M. ( $n=4-8$ /group). $* P<0.05$ vs. untreated (CTRL); $\dagger P<0.05$ mitochondrial vs. cytosolic phospho to total ratio; by one-way ANOVA and Newman-Keuls post-hoc test.

(Khaidakov et al., 2014; Yang et al., 2016) or protection (Most et al., 2003). Yang et al. (2016) found, for example, that $80 \mu \mathrm{M}$ dynasore reduced internalization of cardioprotective ATPsensitive potassium channels and infarct development during myocardial I-R. The drug is nonetheless attributed with dynamin-independent effects, including inhibition of membrane ruffling, destabilization of $\mathrm{F}$-actin, and disruption of lipid rafts (Preta et al., 2015). The latter rafts are particularly important to cardiac- and mitochondrial-stress resistance (Fridolfsson et al., 2014; Schilling et al., 2015).

MDIVI-1 likewise inhibits dynamin-dependent GTPase activity, with an $\mathrm{IC}_{50}$ of $1-10 \mu \mathrm{M}$ in yeast (consistent with that for fission inhibition) (Cassidy-Stone et al., 2008), and a $\mathrm{K}_{\mathrm{i}}$ of $15 \mu \mathrm{M}$ for mammalian DRP-1 GTPase activity (Numadate et al., 2014). In contrast, although Bordt et al. (2017) confirmed similar potency of MDIVI-1 in yeast, they found negligible inhibitory effects on mammalian activity $\left(\mathrm{K}_{\mathrm{i}} \geq 1 \mathrm{mM}\right)$. There is also evidence MDIVI-1 may inhibit cardiac $\mathrm{K}^{+}$currents with an $\mathrm{IC}_{50}$ of approx. $12 \mu \mathrm{M}$ (So et al., 2012 ) and inhibit complex I respiration and reactive oxygen species (ROS) generation independently of DRP-1 at $10-50 \mu \mathrm{M}$ concentrations (Bordt et al., 2017), although Zhang et al. (2017) found such effects (together with increased proton leak) are DRP-1-dependent. We found no evidence for modulation of complex I in pre- or postischemic hearts or unstressed cells, although MDIVI-1 preserved the complex I flux-control ratio in reperfused hearts, and both inhibitors augmented proton leak in stressed cells (Fig. 11). Manczak et al. (2019) more recently provided support for specific inhibition of DRP-1 and mitochondrial fragmentation with MDIVI-1; however, they also confirmed differential outcomes with differing MDIVI-1 concentrations: cytoprotection at $25 \mu \mathrm{M}$ versus worsened oxidative stress and ATP depletion with $75 \mu \mathrm{M}$. Smith and Gallo (2017) recently concluded that a weight of published evidence supports selective activity of $\leq 25 \mu \mathrm{M}$ MDIVI-1 toward DRP-1 and fission, although they highlight counter evidence and the importance of publishing negative results challenging this view. As discussed below, MDIVI-1 induces complex effects on multiple determinants of stress resistance.

Mitochondrial Function. Bidirectional relationships exist between mitochondrial respiration and dynamism. Although excessive fission can be detrimental, moderately increased fission improves cardiac mitochondrial coupling and function (Papanicolaou et al., 2012), and DRP-1 inhibition induces respiratory dysfunction (Benard et al., 2007). Such 

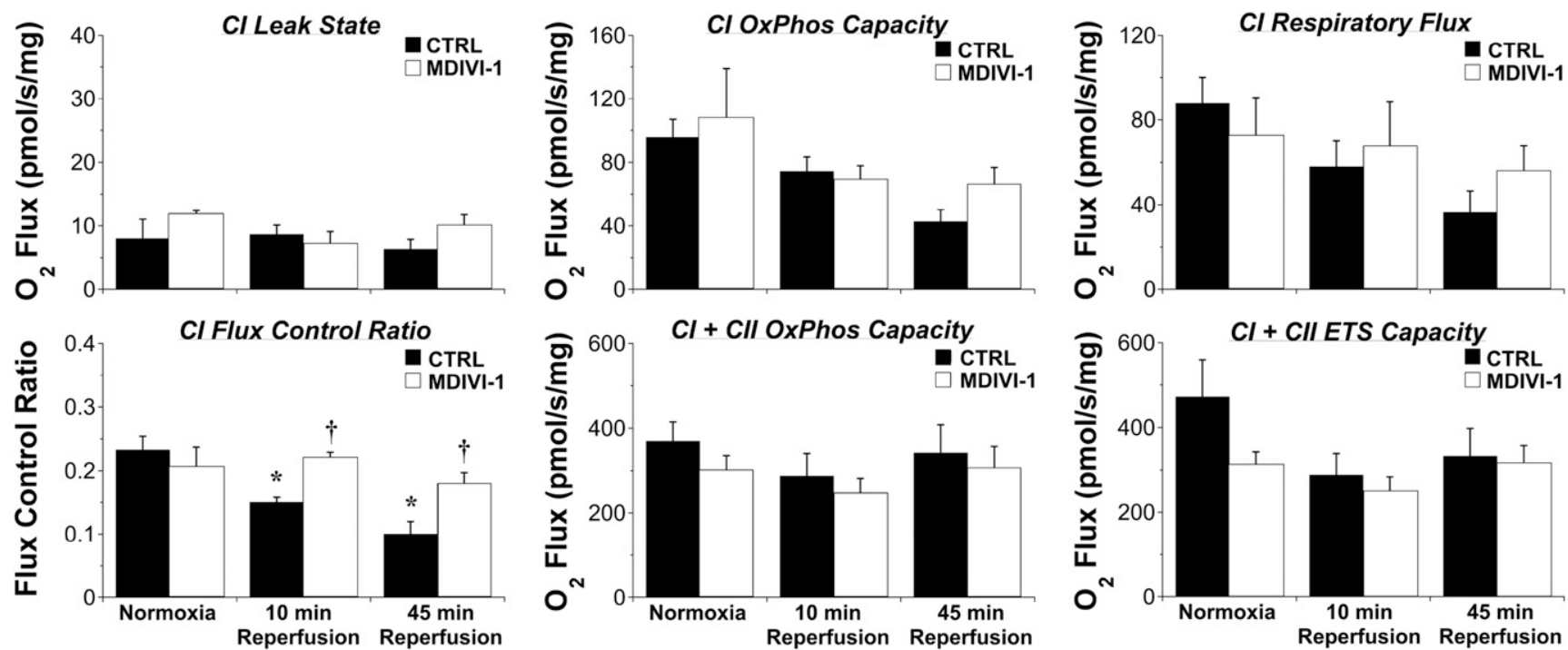

Fig. 7. Effects of I-R and MDIVI-1 on mitochondrial respiration. Hearts were perfused under normoxic conditions or reperfused for 10 or 45 minutes following 25 minutes' ischemia. Perfused hearts were untreated (CTRL) or exposed to $1 \mu \mathrm{M}$ MDIVI-1 10 minutes prior to and throughout I-R. Data are shown for: complex I leak state (addition of $5 \mathrm{mM}$ pyruvate/2 $\mathrm{mM}$ malate/10 mM glutamate), complex I oxidative phosphorylation (OxPhos) capacity (addition of $5 \mathrm{mM} \mathrm{ADP),} \mathrm{complex} \mathrm{I} \mathrm{respiratory} \mathrm{flux} \mathrm{[electron} \mathrm{transfer} \mathrm{system} \mathrm{(ETS)} \mathrm{capacity} \mathrm{-} \mathrm{Leak),} \mathrm{complex} \mathrm{I} \mathrm{flux} \mathrm{control} \mathrm{ratio} \mathrm{(normalized} \mathrm{to}$ uncoupled respiration upon addition of FCCP), complex I + complex II OxPhos capacity (10 mM succinate/5 mM ADP), and complex I + complex II ETS capacity (addition of $0.5 \mu \mathrm{M}$ FCCP). Oxygen flux values are normalized to milligrams of ventricular tissue per chamber. Data are means \pm S.E.M. $(n=$ 4-8/group). $* P<0.05$ vs. normoxia; $\dagger P<0.05$ vs. untreated (CTRL); by one-way ANOVA and Newman-Keuls post-hoc test.

dysfunction promotes mitochondrial fission (Benard et al., 2007; Plecitá-Hlavata et al., 2008; Wang et al., 2012; Toyama et al., 2016) and inter-related autophagy (Chu et al., 2013; Kagan et al., 2016). However, Disatnik et al. (2013) reported improved state 3 (equivalent to complex I) respiratory activity with the DRP-1 inhibitor P110 in postischemic myocardium, and Ding et al. (2017) reported improved postischemic
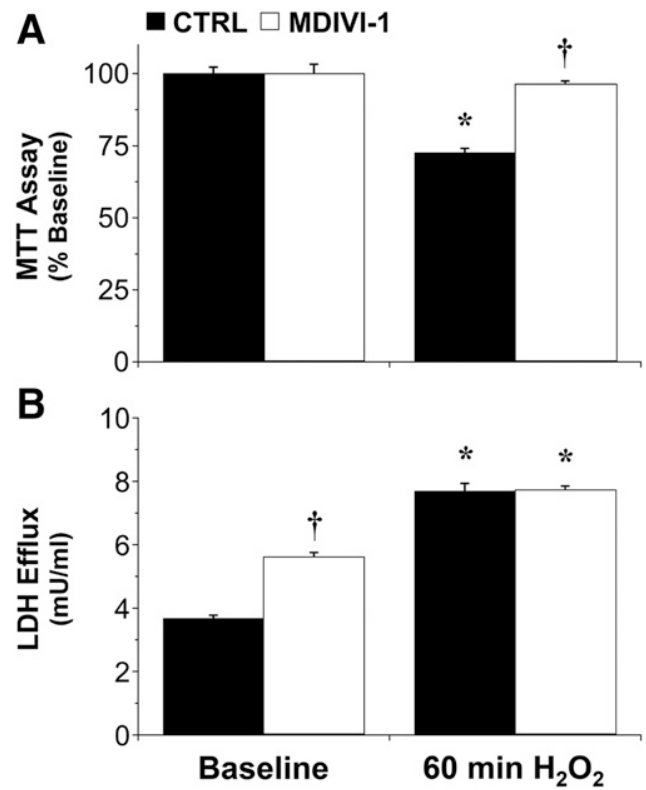

Fig. 8. Effects of MDIVI-1 on metabolic activity and cell death in H9c2 cardiomyoblasts exposed to $\mathrm{H}_{2} \mathrm{O}_{2}$. Cells were pretreated with vehicle (CTRL) or $50 \mu \mathrm{M}$ MDIVI-1 prior to 60 minutes' $\mathrm{H}_{2} \mathrm{O}_{2}$ exposure $(400 \mu \mathrm{M})$. Data are shown for: (A) cellular metabolic activity (MTT assay, relative to baseline) and (B) cell death (total LDH efflux). Data are means \pm S.E.M. $(n=3)$. $* P<0.05$ vs. baseline; $\dagger P<0.05$ vs. untreated (CTRL); by one-way ANOVA and Newman-Keuls post-hoc test. respiratory function in hearts of diabetic mice treated with MDIVI-1. Thus, whether DRP-1 inhibition improves mitochondrial function is equivocal and may depend upon degree and type of stress. Here normoxic and postischemic respiratory fluxes were not significantly modified by selective concentrations of MDIVI-1, although complex I flux control was protected, reflecting improved coupling and potentially limiting ROS generation (Jheng et al., 2012; Sharp et al., 2014; Wang et al., 2014). Observations in rat cardiomyoblasts support both mitochondrial benefit and detriment, with MDIVI-1 preserving basal respiration during $\mathrm{H}_{2} \mathrm{O}_{2}$ stress, whereas MDIVI-1 and dynasore both increased proton leak and nonmitochondrial $\mathrm{O}_{2}$ consumption. The latter will reduce respiratory efficiency and promote ROS generation, consistent with effects of DRP-1 knockdown (Benard et al., 2007), protection with increased fission (Papanicolaou et al., 2012), and increased basal respiration and proton leak in DRP-1 and autophagy-deficient nematodes (Luz et al., 2015). Modulation of fission and autophagy proteins with MDIVI-1 (Fig. 9; Table 2) may thus contribute to mixed benefit and dysfunction in mitochondria.

Survival Kinase Signaling. Since regulatory loops also exist between DRP-1 and ERK1/2 and AKT, DRP-1 inhibitors may disrupt reperfusion injury salvage kinase (RISK) pathways that normally limit mitochondrial dysfunction, mitochondrial permeability transition pore (mPTP) activity, and cell death (Hausenloy and Yellon, 2007). Both kinases are linked to fission and DRP-1: ERK1/2 phosphorylates DRP-1 (Kashatus et al., 2015; Serasinghe et al., 2015) and promotes fission in myocytes (Yu et al., 2011a), neuronal cells (Gan et al., 2014), and fibroblasts (Prieto et al., 2016); DRP-1 in turn activates ERK1/2 (Lim et al., 2015); and DRP-1 inhibitors reportedly impair myocardial ERK1/2 signaling and augment AKT signaling (Jheng et al., 2012; Gharanei et al., 2013). There is also some evidence for fusion protein involvement in protection via ERK1/2 (Pyakurel et al., 2015) and PI3K/AKT 

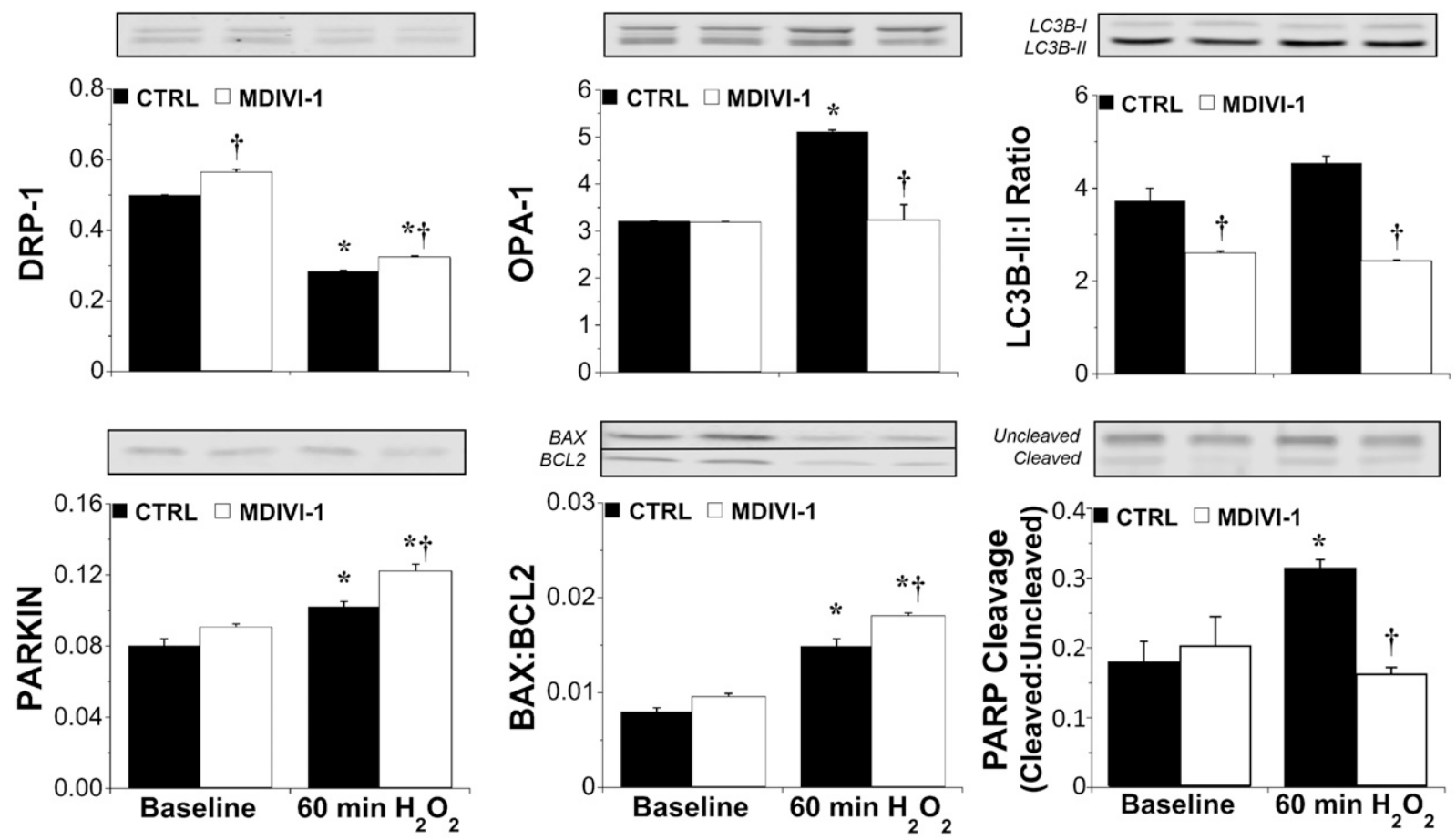

Fig. 9. Effects of MDIVI-1 on fission/fusion, autophagy, and apoptosis proteins in H9c2 cardiomyoblasts exposed to $\mathrm{H}_{2} \mathrm{O}_{2}$. Cells were pretreated with vehicle (CTRL) or $50 \mu \mathrm{M}$ MDIVI-1 prior to 60 minutes' $\mathrm{H}_{2} \mathrm{O}_{2}$ exposure (400 $\mu \mathrm{M}$ ). Cell lysates were assessed for: DRP-1, OPA-1, ratio of LC3B-II/LC3B-I, Parkin, ratio of BAX/BCL2, and PARP cleavage. Protein levels are normalized to GAPDH expression. Immunoblot images shown at the top of each panel. Data are means \pm S.E.M. $(n=3)$. $* P<0.05$ vs. baseline; $\dagger P<0.05$ vs. untreated (CTRL); by one-way ANOVA and Newman-Keuls post-hoc test.

(Ong et al., 2015), although these outcomes may be fusion/ fission-independent (Ong et al., 2017). Effects of MDIVI-1 here confirm linkages between DRP-1 and survival kinases, though effects are model-specific: MDIVI-1 reduced postischemic ERK1/2 activation in hearts and early ERK1/2 activation in stressed myoblasts but augmented late ERK1/2 and AKT phosphorylation in myoblasts. These differential effects may be either beneficial or detrimental-although ERK1/2 is implicated in the protective RISK pathway (Hausenloy and Yellon, 2007), and inhibition of early ERK1/2 activation may suppress early fission (Yu et al., 2011a), exaggeration of late ERK1/2 activation could worsen cell death (Koinzer et al., 2015). On the other hand, increased AKT phosphorylation with MDIVI-1 is predicted to be protective and may influence
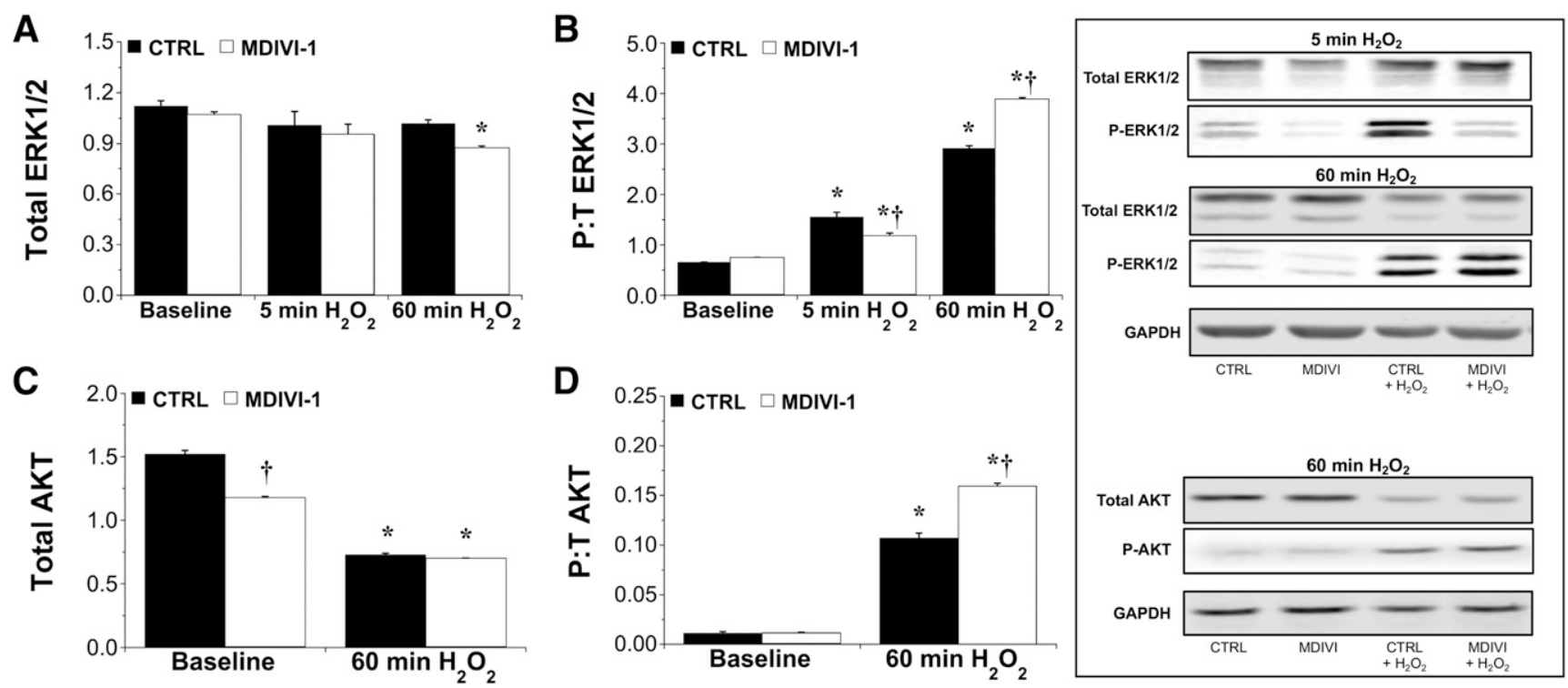

Fig. 10. Effects of MDIVI-1 on survival kinase signaling in $\mathrm{H} 9 \mathrm{c} 2$ cardiomyoblasts exposed to $\mathrm{H}_{2} \mathrm{O}_{2}$. Cells were pretreated with vehicle or $50 \mu \mathrm{M}$ MDIVI1 prior to 60 minutes' exposure to $400 \mu \mathrm{M} \mathrm{H}_{2} \mathrm{O}_{2}$. Cell lysates were assessed for: (A) total ERK1/2, (B) ratio of phosphorylated to total (P:T) ERK1/2, (C) total AKT, and (D) ratio of phosphorylated to total (P:T) AKT. A subset was assessed for changes in early activation of ERK1/2 after 5 minutes' $\mathrm{H}_{2} \mathrm{O}_{2}$ challenge. Right panel shows immunoblots for ERK1/2 (5 and 60 minutes' $\mathrm{H}_{2} \mathrm{O}_{2}$ ) and AKT $\left(60\right.$ minutes' $\mathrm{H}_{2} \mathrm{O}_{2}$ ). Expression normalized to GAPDH. Data are means \pm S.E.M. ( $n=5$ /group). $* P<0.05$ vs. baseline; $\dagger P<0.05$ vs. untreated (CTRL); by one-way ANOVA and Newman-Keuls test. 

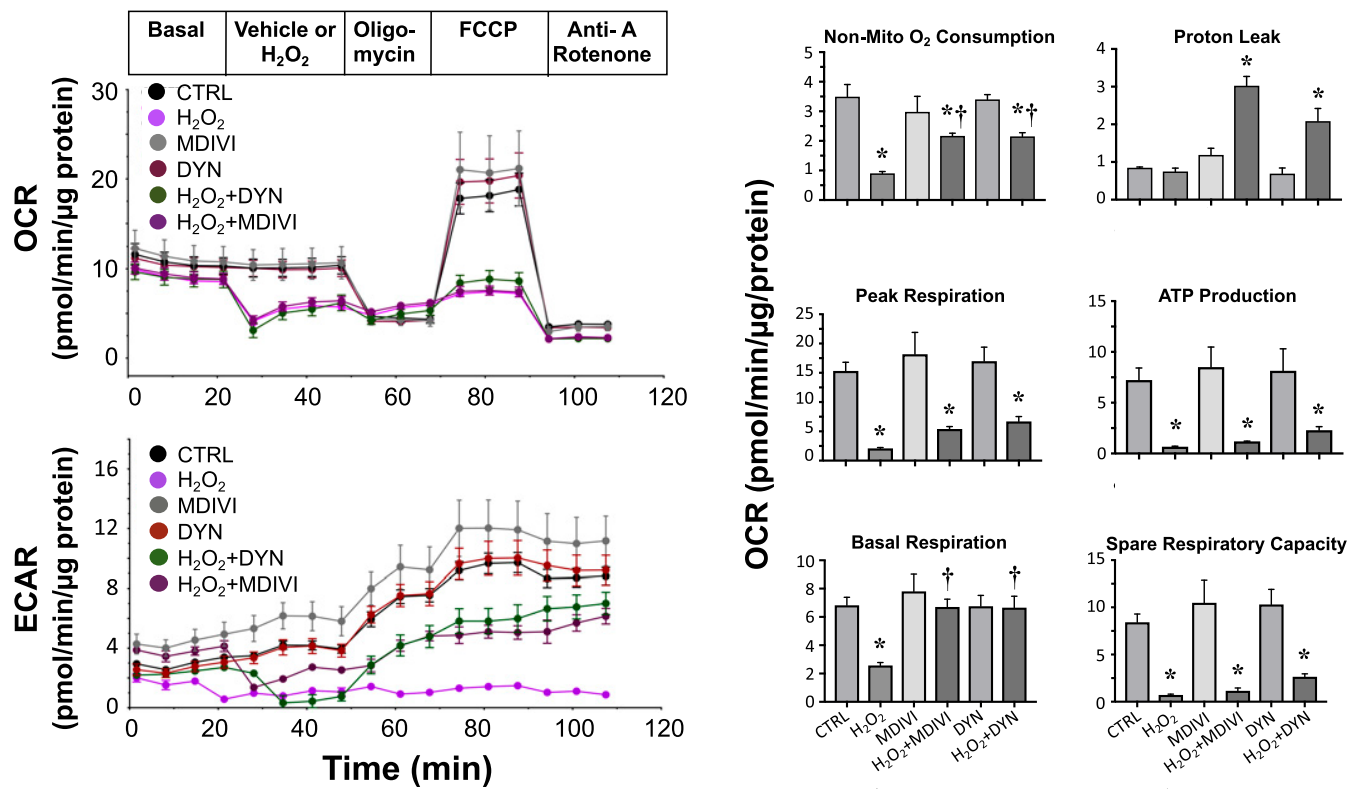

Fig. 11. Effects of MDIVI-1 and dynasore on mitochondrial respiratory function and cellular acidification in $\mathrm{H} 9 \mathrm{c} 2$ cardiomyoblasts exposed to $\mathrm{H}_{2} \mathrm{O}_{2}$. Cells were pretreated with vehicle, $50 \mu \mathrm{M}$ MDIVI-1, or dynasore prior to control conditions or exposure to $400 \mu \mathrm{M} \mathrm{H}_{2} \mathrm{O}_{2}$. (Left panels) Oxygen consumption rate and extracellular acidification rate (indicator of glycolytic metabolism) were monitored. (Right panels) The OCR data (picomoles per minute per microgram protein per well) were used to calculate respiratory parameters as indicated in Materials and Methods. Data are means \pm S.E.M. ( $n=3$-5/group). $* P<0.05$ vs. control (Ctrl); $\uparrow P<0.05 \mathrm{vs}_{2} \mathrm{O}_{2}$; by one-way ANOVA and Newman-Keuls post-hoc test.

fusion proteins (Ong and Hausenloy, 2010; Ong et al., 2015). Gharanei et al. (2013) reported augmented myocardial AKT activation with MDIVI-1, inconsistent with insensitivity of cardiac AKT here (Fig. 6), though consistent with effects in myoblasts (Fig. 9). Disrupted kinase signaling may contribute to the mixed impacts of DRP-1 inhibition on stress responses. The basis of distinct effects in postischemic hearts versus stressed myoblasts is unknown, though may involve differences in models, insults, and concentrations of MDIVI-1 employed.

Autophagy Proteins. Elevations in LC3B-II and Parkin in $\mathrm{H}_{2} \mathrm{O}_{2}$ treated myoblasts (Fig. 9) are consistent with stressdependent induction of autophagy (Ha et al., 2012). This process governs mitochondrial function (Gottlieb and Gustafsson, 2011; Dutta et al., 2013), ischemic tolerance, and cardioprotection (Moyzis et al., 2015). Nonetheless, autophagy may also promote (Adhami et al., 2006; Wen et al., 2008) or inhibit I-R injury (Zhang et al., 2013; Yun et al., 2014). Moreover, although inhibition, deletion, or mutation of DRP1 inhibits autophagy (Arnoult et al., 2005; Twig et al., 2008; Dagda et al., 2009), effects of DRP-1 versus fission on this process and related cell death paths remain contentious within and across cell types. For example, fission may inhibit
(Song et al., 2015) or promote (Ikeda et al., 2015) autophagy and death in cardiac cells, promote autophagy while inhibiting death in neuronal cells (Zhang et al., 2013), and conversely inhibit autophagy while promoting death in renal cells (Lee et al., 2016). The response of autophagy proteins to $\mathrm{H}_{2} \mathrm{O}_{2}$ was differentially modified by MDIVI-1: Reductions in LC3B-II and the LC3B-II/-I ratio suggest repressed autophagosome formation, consistent with reported effects of DRP-1 inhibition or knockdown (Twig et al., 2008; Zhang et al., 2013; Song et al., 2015), and an observed decline in PARP (which normally promotes autophagy; Fig. 9). Conversely, observed Parkin upregulation may favor autophagy, although elevated Parkin does not necessarily induce mitophagy (Morán et al., 2014), and DRP-1 may be more important in Parkin-independent autophagy (Kageyama et al., 2014). There is also evidence Parkin can stimulate DRP-1-dependent fission (Yu et al., 2011(Yu et al., 2011b); Buhlman et al., 2014), thus upregulation may compensate in part for DRP-1 inhibition.

Cell Death Proteins. Since DRP-1 and fission also influence apoptosis, DRP-1 inhibitors were predicted to modulate apoptosis proteins. DRP-1 colocalizes with BAX (Karbowski et al., 2002) and promotes BAX/BAK-induced cytochrome $c$ release (Clerc et al., 2014), and fragmentation

TABLE 2

Summary of MDIVI-1 effects in mouse hearts subjected to I-R and rat cardiomyoblasts exposed to $\mathrm{H}_{2} \mathrm{O}_{2}$

\begin{tabular}{|c|c|c|}
\hline Parameter/Protein & Myocardial I-R & Myoblast Oxidative Stress \\
\hline $\begin{array}{l}\text { Contractile or metabolic } \\
\text { function }\end{array}$ & $\begin{array}{c}\Downarrow \text { Contracture }(5 \mu \mathrm{M}), \Uparrow \mathrm{LVP}(1 \mu \mathrm{M}), \Downarrow \mathrm{LVP} \\
(5 \mu \mathrm{M})\end{array}$ & $\Uparrow \mathrm{MTT}$ \\
\hline Necrosis (LDH efflux) & Delayed $(1 \mu \mathrm{M}), \Downarrow(5 \mu \mathrm{M})$ & $\Leftrightarrow$ \\
\hline Mitochondrial function & $\Uparrow \mathrm{CI}$ flux control & $\begin{array}{c}\Uparrow \Delta \psi_{\mathrm{m}}, \Uparrow \text { Basal OCR, } \Uparrow \text { Non-Mito OCR, } \\
\text { Proton leak }\end{array}$ \\
\hline Fission/fusion & $\Downarrow \mathrm{DRP}-1$ & $\Downarrow \mathrm{DRP}-1, \Uparrow$ OPA-1 \\
\hline Survival kinases & $\Downarrow \mathrm{P}$-ERK & $\Uparrow \mathrm{P}-\mathrm{AKT}, \Uparrow$ Late P-ERK, $\Downarrow$ Early P-ERK \\
\hline Autophagy & - & $\Uparrow$ Parkin, $\Downarrow$ LC3B-II, $\Downarrow$ LC3B-II/I \\
\hline Apoptosis & - & $\Downarrow$ PARP cleavage, $\Uparrow$ BAX/BCL2 \\
\hline
\end{tabular}


during apoptosis is DRP-1-dependent (Frank et al., 2001). Nonetheless, fission and DRP-1 may be dispensable in apoptotic death (Parone et al., 2006; Ishihara et al., 2009) and reportedly inhibit (Szabadkai et al., 2004) and promote (Lee et al., 2016) apoptosis in different cells. As for kinase signaling and autophagy, MDIVI-1 differentially modified cell death determinants, countering PARP cleavage and exaggerating $\mathrm{BAX} / \mathrm{BCL} 2$ responses to $\mathrm{H}_{2} \mathrm{O}_{2}$ in cardiomyoblasts. How these changes influence death versus survival is unclearalthough increased BAX/BCL2 may promote apoptosis, reduced downstream PARP cleavage suggests a reduction in caspase activation. Inhibition of PARP cleavage has also been shown to induce necrosis (Herceg and Wang, 1999), with cleavage potentially serving as a switch between necrotic and apoptotic paths, while inhibiting necroptosis and parthanatos (Aredia and Scovassi, 2014). Suppression of cleavage by MDIVI-1 may thus exaggerate necrosis/necroptosis and limit apoptosis, congruently with observations in stressed myocytes (Dong et al., 2016). Reduced cleavage may also favor autophagy and increase NAD consumption (Aredia and Scovassi, 2014), further influencing mitochondrial function and cell death. The effects of fission or DRP-1 on these processes warrant further study, as mixed impacts of MDIVI-1 may reflect opposing shifts in death pathways (Dong et al., 2016).

Evidence of a biphasic pattern of early ischemic fission followed by a postischemic wave preceding death (Kumar et al., 2016) is relevant when considering effects of DRP-1 (Zhang et al., 2013; Dong et al., 2016). Early fission may be activated by rapid mitochondrial depolarization/inhibition (Benard et al., 2007; Plecitá-Hlavata et al., 2008; Wang et al., 2012; Toyama et al., 2016) during ischemia and could trigger cell death. However, whether this or the later postischemic wave of fission (Kumar et al., 2016) facilitates apoptosis without playing essential roles (Parone et al., 2006; Ishihara et al., 2009) is also unclear. Interestingly, analysis of rotenone-dependent complex I inhibition (Benard et al., 2007) supports a clear transition in mitochondrial morphology at the threshold to cell death consistent with fission.

\section{Conclusions}

The fission inhibitor MDIVI-1 reduces mitochondrial DRP-1 levels in postischemic myocardium and improves mitochondrial control and function in both heart and cardiomyoblasts. Nonetheless, MDIVI-1 and dynasore produce complex outcomes in stressed hearts and cells, including differential changes in cell death versus dysfunction, and survivalkinase, autophagy, and cell death signaling. These observations raise important questions regarding the selectivity, mechanisms of action, and broader cardioprotective utility of putative DRP-1 inhibitors.

\section{Authorship Contributions}

Participated in research design: Wendt, Du Toit, Peart, Headrick. Conducted experiments: Wendt, Vider, See Hoe, Headrick. Performed data analysis: Wendt, Vider, Peart, Headrick.

Wrote or contributed to writing of the manuscript: Wendt, Du Toit, Peart, Headrick.

\section{References}

Adhami F, Liao G, Morozov YM, Schloemer A, Schmithorst VJ, Lorenz JN, Dunn RS, Vorhees CV, Wills-Karp M, Degen JL, et al. (2006) Cerebral ischemia-hypoxia induces intravascular coagulation and autophagy. Am J Pathol 169:566-583.
Aredia F and Scovassi AI (2014) Poly(ADP-ribose): a signaling molecule in different paradigms of cell death. Biochem Pharmacol 92:157-163.

Arnoult D, Rismanchi N, Grodet A, Roberts RG, Seeburg DP, Estaquier J, Sheng M, and Blackstone C (2005) Bax/Bak-dependent release of DDP/TIMM8a promotes Drp1-mediated mitochondrial fission and mitoptosis during programmed cell death. Curr Biol 15:2112-2118.

Benard G, Bellance N, James D, Parrone P, Fernandez H, Letellier T, and Rossignol R (2007) Mitochondrial bioenergetics and structural network organization. J Cell Sci 120:838-848.

Biala AK, Dhingra R, and Kirshenbaum LA (2015) Mitochondrial dynamics: orchestrating the journey to advanced age. J Mol Cell Cardiol 83:37-43.

Bordt EA, Clerc P, Roelofs BA, Saladino AJ, Tretter L, Adam-Vizi V, Cherok E, Khalil A, Yadava N, Ge SX, et al. (2017) The Putative Drp1 inhibitor mdivi-1 Is a reversible mitochondrial complex $\mathrm{i}$ inhibitor that modulates reactive oxygen species. Dev Cell 40:583-594.e6.

Buhlman L, Damiano M, Bertolin G, Ferrando-Miguel R, Lombès A, Brice A, and Corti $\mathrm{O}$ (2014) Functional interplay between Parkin and Drp1 in mitochondria fission and clearance. Biochim Biophys Acta 1843:2012-2026.

Cassidy-Stone A, Chipuk JE, Ingerman E, Song C, Yoo C, Kuwana T, Kurth MJ, Shaw JT, Hinshaw JE, Green DR, et al. (2008) Chemical inhibition of the mitochondrial division dynamin reveals its role in Bax/Bak-dependent mitochondrial outer membrane permeabilization. Dev Cell 14:193-204.

Chen H, Chomyn A, and Chan DC (2005) Disruption of fusion results in mitochondrial heterogeneity and dysfunction. J Biol Chem 280:26185-26192.

Chu CT, Ji J, Dagda RK, Jiang JF, Tyurina YY, Kapralov AA, Tyurin VA, Yanamala N, Shrivastava IH, Mohammadyani D, et al. (2013) Cardiolipin externalization to the outer mitochondrial membrane acts as an elimination signal for mitophagy in neuronal cells. Nat Cell Biol 15:1197-1205.

Clerc P, Ge SX, Hwang H, Waddell J, Roelofs BA, Karbowski M, Sesaki H, and Polster BM (2014) Drp1 is dispensable for apoptotic cytochrome c release in primed MCF10A and fibroblast cells but affects Bcl-2 antagonist-induced respiratory changes. Br J Pharmacol 171:1988-1999.

Dagda RK, Cherra SJ III, Kulich SM, Tandon A, Park D, and Chu CT (2009) Loss of PINK1 function promotes mitophagy through effects on oxidative stress and mitochondrial fission. J Biol Chem 284:13843-13855.

Ding M, Dong Q, Liu Z, Liu Z, Qu Y, Li X, Huo C, Jia X, Fu F, and Wang X (2017) Inhibition of dynamin-related protein 1 protects against myocardial ischemiareperfusion injury in diabetic mice. Cardiovasc Diabetol 16 (1):19, doi: 10.1186/ s12933-017-0501-2 28173848.

Disatnik MH, Ferreira JCB, Campos JC, Gomes KS, Dourado PMM, Qi X, and Mochly-Rosen D (2013) Acute inhibition of excessive mitochondrial fission after myocardial infarction prevents long-term cardiac dysfunction. J Am Heart Assoc 2:e000461.

Dong Y, Undyala VVR, and Przyklenk K (2016) Inhibition of mitochondrial fission as a molecular target for cardioprotection: critical importance of the timing of treatment. Basic Res Cardiol 111:59.

Dorn GW II (2015) Mitochondrial dynamism and heart disease: changing shape and shaping change. EMBO Mol Med 7:865-877.

Dorn GW II and Kitsis RN (2015) The mitochondrial dynamism-mitophagy-cell death interactome: multiple roles performed by members of a mitochondrial molecular ensemble. Circ Res 116:167-182.

Dutta D, Xu J, Kim JS, Dunn WA Jr, and Leeuwenburgh C (2013) Upregulated autophagy protects cardiomyocytes from oxidative stress-induced toxicity. Autophagy 9:328-344.

Frank S, Gaume B, Bergmann-Leitner ES, Leitner WW, Robert EG, Catez F, Smith CL, and Youle RJ (2001) The role of dynamin-related protein 1, a mediator of mitochondrial fission, in apoptosis. Dev Cell 1:515-525.

Fridolfsson HN, Roth DM, Insel PA, and Patel HH (2014) Regulation of intracellular signaling and function by caveolin. FASEB $J$ 28:3823-3831.

Gan X, Huang S, Wu L, Wang Y, Hu G, Li G, Zhang H, Yu H, Swerdlow RH, Chen JX, et al. (2014) Inhibition of ERK-DLP1 signaling and mitochondrial division alleviates mitochondrial dysfunction in Alzheimer's disease cybrid cell. Biochim Biophys Acta 1842:220-231.

Gao D, Yang J, Wu Y, Wang Q, Wang Q, Lai EY, and Zhu J (2016) Targeting Dynamin 2 as a novel pathway to inhibit cardiomyocyte apoptosis following oxidative stress. Cell Physiol Biochem 39:2121-2134.

Gao D, Zhang L, Dhillon R, Hong TT, Shaw RM, and Zhu J (2013) Dynasore protects mitochondria and improves cardiac lusitropy in Langendorff perfused mouse heart. PLoS One 8:e60967.

Gharanei M, Hussain A, Janneh O, and Maddock H (2013) Attenuation of doxorubicin-induced cardiotoxicity by mdivi-1: a mitochondrial division/mitophagy inhibitor. PLoS One 8:e77713.

Gottlieb RA and Gustafsson AB (2011) Mitochondrial turnover in the heart. Biochim Biophys Acta 1813:1295-1301.

Ha JH, Noh HS, Shin IW, Hahm JR, and Kim DR (2012) Mitigation of H2O2-induced autophagic cell death by propofol in H9c2 cardiomyocytes. Cell Biol Toxicol 28:19-29.

Hausenloy DJ and Yellon DM (2007) Preconditioning and postconditioning: united at reperfusion. Pharmacol Ther 116:173-191.

Herceg Z and Wang ZQ (1999) Failure of poly(ADP-ribose) polymerase cleavage by caspases leads to induction of necrosis and enhanced apoptosis. Mol Cell Biol 19: $5124-5133$

Ikeda Y, Shirakabe A, Maejima Y, Zhai P, Sciarretta S, Toli J, Nomura M, Mihara K, Egashira K, Ohishi M, et al. (2015) Endogenous Drp1 mediates mitochondrial autophagy and protects the heart against energy stress. Circ Res 116:264-278.

Ishihara N, Nomura M, Jofuku A, Kato H, Suzuki SO, Masuda K, Otera H, Nakanishi Y, Nonaka I, Goto Y, et al. (2009) Mitochondrial fission factor Drp1 is essential for embryonic development and synapse formation in mice. Nat Cell Biol 11:958-966.

Jheng HF, Tsai PJ, Guo SM, Kuo LH, Chang CS, Su IJ, Chang CR, and Tsai YS (2012) Mitochondrial fission contributes to mitochondrial dysfunction and insulin resistance in skeletal muscle. Mol Cell Biol 32:309-319. 
Kagan VE, Jiang J, Huang Z, Tyurina YY, Desbourdes C, Cottet-Rousselle C, Dar HH, Verma M, Tyurin VA, Kapralov AA, et al. (2016) NDPK-D (NM23-H4)-mediated externalization of cardiolipin enables elimination of depolarized mitochondria by mitophagy. Cell Death Differ 23:1140-1151.

Kageyama Y, Hoshijima M, Seo K, Bedja D, Sysa-Shah P, Andrabi SA, Chen W, Höke A, Dawson VL, Dawson TM, et al. (2014) Parkin-independent mitophagy requires Drp1 and maintains the integrity of mammalian heart and brain. EMBO J $\mathbf{3 3}$ 2798-2813.

Karbowski M, Lee YJ, Gaume B, Jeong SY, Frank S, Nechushtan A, Santel A, Fuller M, Smith CL, and Youle RJ (2002) Spatial and temporal association of Bax with mitochondrial fission sites, Drp1, and Mfn2 during apoptosis. J Cell Biol 159: 931-938.

Kashatus JA, Nascimento A, Myers LJ, Sher A, Byrne FL, Hoehn KL, Counter CM, and Kashatus DF (2015) Erk2 phosphorylation of Drp1 promotes mitochondrial fission and MAPK-driven tumor growth. Mol Cell 57:537-551.

Khaidakov M, Mercanti F, Wang X, Ding Z, Dai Y, Romeo F, Sawamura T, and Mehta JL (2014) Prevention of export of anoxia/reoxygenation injury from ischemic to nonischemic cardiomyocytes via inhibition of endocytosis. Am J Physiol Heart Circ Physiol 306:H1700-H1707.

Koinzer S, Reinecke K, Herdegen T, Roider J, and Klettner A (2015) Oxidative stress induces biphasic ERK1/2 activation in the RPE with distinct effects on cell survival at early and late activation. Curr Eye Res 40:853-857.

Kumar R, Bukowski MJ, Wider JM, Reynolds CA, Calo L, Lepore B, Tousignant R, Jones M, Przyklenk K, and Sanderson TH (2016) Mitochondrial dynamics following global cerebral ischemia. Mol Cell Neurosci 76:68-75.

Lee WC, Chiu CH, Chen JB, Chen CH, and Chang HW (2016) Mitochondrial fission increases apoptosis and decreases autophagy in renal proximal tubular epithelial cells treated with high glucose. DNA Cell Biol 35:657-665.

Lim S, Lee SY, Seo HH, Ham O, Lee C, Park JH, Lee J, Seung M, Yun I, Han SM, et al. (2015) Regulation of mitochondrial morphology by positive feedback interaction between PKC $\delta$ and Drp1 in vascular smooth muscle cell. J Cell Biochem 116:648-660

Luz AL, Rooney JP, Kubik LL, Gonzalez CP, Song DH, and Meyer JN (2015) Mitochondrial morphology and fundamental parameters of the mitochondrial respiratory chain are altered in Caenorhabditis elegans strains deficient in mitochondrial dynamics and homeostasis processes. PLoS One 10:e0130940.

Macia E, Ehrlich M, Massol R, Boucrot E, Brunner C, and Kirchhausen T (2006) Dynasore, a cell-permeable inhibitor of dynamin. Dev Cell 10:839-850.

Manczak M, Kandimalla R, Yin X, and Reddy PH (2019) Mitochondrial division inhibitor 1 reduces dynamin-related protein 1 and mitochondrial fission activity. Hum Mol Genet 28:177-199.

Marín-García J and Akhmedov AT (2016) Mitochondrial dynamics and cell death in heart failure. Heart Fail Rev 21:123-136.

Morán M, Delmiro A, Blázquez A, Ugalde C, Arenas J, and Martín MA (2014) Bulk autophagy, but not mitophagy, is increased in cellular model of mitochondria disease. Biochim Biophys Acta 1842:1059-1070.

Most P, Boerries M, Eicher C, Schweda C, Ehlermann P, Pleger ST, Loeffler E, Koch WJ, Katus HA, Schoenenberger CA, et al. (2003) Extracellular S100A1 protein inhibits apoptosis in ventricular cardiomyocytes via activation of the extracellular signal-regulated protein kinase 1/2 (ERK1/2). J Biol Chem 278:48404-48412.

Moyzis AG, Sadoshima J, and Gustafsson AB (2015) Mending a broken heart: the role of mitophagy in cardioprotection. Am $J$ Physiol Heart Circ Physiol 308 H183-H192.

Numadate A, Mita Y, Matsumoto Y, Fujii S, and Hashimoto Y (2014) Development of 2-thioxoquinazoline-4-one derivatives as dual and selective inhibitors of dynaminrelated protein 1 (Drp1) and puromycin-sensitive aminopeptidase (PSA). Chem Pharm Bull (Tokyo) 62:979-988.

Ong SB, Hall AR, Dongworth RK, Kalkhoran S, Pyakurel A, Scorrano L, and Hausenloy DJ (2015) Akt protects the heart against ischaemia-reperfusion injury by modulating mitochondrial morphology. Thromb Haemost 113:513-521.

Ong SB and Hausenloy DJ (2010) Mitochondrial morphology and cardiovascular disease. Cardiovasc Res 88:16-29.

Ong SB, Kalkhoran SB, Hernández-Reséndiz S, Samangouei P, Ong SG, and Hausenloy DJ (2017) Mitochondrial-shaping proteins in cardiac health and disease - the long and the short of it!. Cardiovasc Drugs Ther 31:87-107.

Ong SB, Subrayan S, Lim SY, Yellon DM, Davidson SM, and Hausenloy DJ (2010) Inhibiting mitochondrial fission protects the heart against ischemia/reperfusion injury. Circulation 121:2012-2022.

Papanicolaou KN, Ngoh GA, Dabkowski ER, O'Connell KA, Ribeiro RF Jr, Stanley WC, and Walsh K (2012) Cardiomyocyte deletion of mitofusin-1 leads to mitochondrial fragmentation and improves tolerance to ROS-induced mitochondrial dysfunction and cell death. Am J Physiol Heart Circ Physiol $\mathbf{3 0 2}$ H167-H179.

Parone PA, James DI, Da Cruz S, Mattenberger Y, Donzé O, Barja F, and Martinou JC (2006) Inhibiting the mitochondrial fission machinery does not prevent $\mathrm{Bax} /$ Bak-dependent apoptosis. Mol Cell Biol 26:7397-7408.

Peart J and Headrick JP (2003) Adenosine-mediated early preconditioning in mouse: protective signaling and concentration dependent effects. Cardiovasc Res $\mathbf{5 8}$ 589-601.

Plecitá-Hlavatá L, Lessard M, Santorová J, Bewersdorf J, and Jezek P (2008) Mitochondrial oxidative phosphorylation and energetic status are reflected by mor phology of mitochondrial network in INS-1E and HEP-G2 cells viewed by $4 \mathrm{Pi}$ microscopy. Biochim Biophys Acta 1777:834-846.

Preta G, Cronin JG, and Sheldon IM (2015) Dynasore - not just a dynamin inhibitor. Cell Commun Signal 13:24.
Prieto J, León M, Ponsoda X, Sendra R, Bort R, Ferrer-Lorente R, Raya A, LópezGarcía C, and Torres J (2016) Early ERK1/2 activation promotes DRP1-dependent mitochondrial fission necessary for cell reprogramming. Nat Commun 7:11124.

Pyakurel A, Savoia C, Hess D, and Scorrano L (2015) Extracellular regulated kinase phosphorylates mitofusin 1 to control mitochondrial morphology and apoptosis. Mol Cell 58:244-254.

Reddy PH (2014) Inhibitors of mitochondrial fission as a therapeutic strategy for diseases with oxidative stress and mitochondrial dysfunction. J Alzheimers Dis 40: $245-256$

Reichelt ME, Willems L, Hack BA, Peart JN, and Headrick JP (2009) Cardiac and coronary function in the Langendorff-perfused mouse heart model. Exp Physiol 94: $54-70$

Rosdah AAK, K Holien J, Delbridge LM, Dusting GJ, and Lim SY (2016) Mitochondrial fission - a drug target for cytoprotection or cytodestruction? Pharmacol Res Perspect 4:e0235.

Schilling JM, Roth DM, and Patel HH (2015) Caveolins in cardioprotection - translatability and mechanisms. $\mathrm{Br} J$ Pharmacol 172:2114-2125.

Serasinghe MN, Wieder SY, Renault TT, Elkholi R, Asciolla JJ, Yao JL, Jabado O, Hoehn K, Kageyama Y, Sesaki H, et al. (2015) Mitochondrial division is requisite to RAS-induced transformation and targeted by oncogenic MAPK pathway inhibitors. Mol Cell 57:521-536.

Sharp WW, Fang YH, Han M, Zhang HJ, Hong Z, Banathy A, Morrow E, Ryan JJ, and Archer SL (2014) Dynamin-related protein 1 (Drp1)-mediated diastolic dysfunction in myocardial ischemia-reperfusion injury: therapeutic benefits of Drp1 inhibition to reduce mitochondrial fission. FASEB J 28:316-326.

Smith G and Gallo G (2017) To mdivi-1 or not to mdivi-1: is that the question? Dev Neurobiol 77:1260-1268

So EC, Hsing CH, Liang CH, and Wu SN (2012) The actions of mdivi-1, an inhibitor of mitochondrial fission, on rapidly activating delayed-rectifier $\mathrm{K}^{+}$current and membrane potential in HL-1 murine atrial cardiomyocytes. Eur J Pharmacol 683 1-9.

Song M and Dorn GW II (2015) Mitoconfusion: noncanonical functioning of dynamism factors in static mitochondria of the heart. Cell Metab 21:195-205.

Song M, Mihara K, Chen Y, Scorrano L, and Dorn GW II (2015) Mitochondrial fission and fusion factors reciprocally orchestrate mitophagic culling in mouse hearts and cultured fibroblasts. Cell Metab 21:273-286.

Szabadkai G, Simoni AM, Chami M, Wieckowski MR, Youle RJ, and Rizzuto R (2004) Drp-1-dependent division of the mitochondrial network blocks intraorganellar $\mathrm{Ca}^{2+}$ waves and protects against $\mathrm{Ca}^{2+}$-mediated apoptosis. Mol Cell 16:59-68.

Taguchi N, Ishihara N, Jofuku A, Oka T, and Mihara K (2007) Mitotic phosphorylation of dynamin-related GTPase Drp1 participates in mitochondrial fission. J Biol Chem 282:11521-11529.

Toyama EQ, Herzig S, Courchet J, Lewis TL Jr, Losón OC, Hellberg K, Young NP Chen H, Polleux F, Chan DC, et al. (2016) Metabolism. AMP-activated protein kinase mediates mitochondrial fission in response to energy stress. Science 351: $275-281$.

Twig G, Elorza A, Molina AJA, Mohamed H, Wikstrom JD, Walzer G, Stiles L, Haigh SE, Katz S, Las G, et al. (2008) Fission and selective fusion govern mitochondrial segregation and elimination by autophagy. EMBO J 27:433-446.

Wang J, Wang P, Li S, Wang S, Li Y, Liang N, and Wang M (2014) Mdivi-1 prevents apoptosis induced by ischemia-reperfusion injury in primary hippocampal cells via inhibition of reactive oxygen species-activated mitochondrial pathway. $J$ Stroke Cerebrovasc Dis 23:1491-1499.

Wang S, Xiao W, Shan S, Jiang C, Chen M, Zhang Y, Lü S, Chen J, Zhang C, Chen Q, et al. (2012) Multi-patterned dynamics of mitochondrial fission and fusion in a living cell. PLoS One 7:e19879.

Wen YD, Sheng R, Zhang LS, Han R, Zhang X, Zhang XD, Han F, Fukunaga K and Qin ZH (2008) Neuronal injury in rat model of permanent focal cerebral ischemia is associated with activation of autophagic and lysosomal pathways. Autophagy 4:762-769.

Yang HQ, Foster MN, Jana K, Ho J, Rindler MJ, and Coetzee WA (2016) Plasticity of sarcolemmal $\mathrm{K}_{\mathrm{ATP}}$ channel surface expression: relevance during ischemia and ischemic preconditioning. Am J Physiol Heart Circ Physiol 310:H1558-H1566.

Yu T, Jhun BS, and Yoon Y (2011a) High-glucose stimulation increases reactive oxygen species production through the calcium and mitogen-activated protein kinase-mediated activation of mitochondrial fission. Antioxid Redox Signal 14: 425-437.

Yu W, Sun Y, Guo S, and Lu B (2011b) The PINK1/Parkin pathway regulates mitochondrial dynamics and function in mammalian hippocampal and dopaminergic neurons. Hum Mol Genet 20:3227-3240.

Yun N, Cho HI, and Lee SM (2014) Impaired autophagy contributes to hepatocellular damage during ischemia/reperfusion: heme oxygenase-1 as a possible regulator. Free Radic Biol Med 68:168-177.

Zhang H, Wang P, Bisetto S, Yoon Y, Chen Q, Sheu SS, and Wang W (2017) A novel fission-independent role of dynamin-related protein 1 in cardiac mitochondrial respiration. Cardiovasc Res 113:160-170.

Zhang X, Yan H, Yuan Y, Gao J, Shen Z, Cheng Y, Shen Y, Wang RR, Wang X, Hu WW, et al. (2013) Cerebral ischemia-reperfusion-induced autophagy protect against neuronal injury by mitochondrial clearance. Autophagy 9:1321-1333.

Address correspondence to: Dr. John P. Headrick, School of Medical Science, Griffith University, Southport, QLD 4217, Australia. E-mail: J.Headrick@ griffith.edu.au 